\title{
Mesosphere Ozone and the Lower Ionosphere under Plasma Disturbance by Powerful High-Frequency Radio Emission
}

\author{
Nataliya V. Bakhmetieva ${ }^{1, *}$, Yuri Yu. Kulikov ${ }^{2, *}$ and Ilia N. Zhemyakov ${ }^{1}$ \\ 1 Radiophysical Research Institute, Nizhny Novgorod State University, 25/12a Bolshaya Pechrskaya Str., \\ 603950 Nizhny Novgorod, Russia; ilia.zhem@yandex.ru \\ 2 Federal Research Center, Institute of Applied Physics of the Russian Academy of Sciences, 46 Ulyanov Str., \\ 603950 Nizhny Novgorod, Russia \\ * Correspondence: nv_bakhm@nirfi.unn.ru (N.V.B.); yuyukul@appl.sci-nnov.ru (Y.Y.K.)
}

Received: 17 September 2020; Accepted: 22 October 2020; Published: 26 October 2020

\begin{abstract}
We present the results of experiments on the Earth's lower ionosphere at mesospheric heights by creating artificial periodic irregularities (APIs) of the ionospheric plasma and simultaneous measurement of the atmospheric emission spectrum in the ozone line by ground-based microwave radiometry when the ionosphere was disturbed by powerful high-frequency radio emission from the midlatitude SURA heating facility $\left(56.15^{\circ} \mathrm{N} ; 46.11^{\circ} \mathrm{E}\right)$. The diagnostics of the ionosphere was carried out on the basis of measuring amplitudes and phases of signals scattered by periodic irregularities in the altitude range of $50-130 \mathrm{~km}$. For each heating session lasting $30 \mathrm{~min}$, two ozone spectra were measured. These spectra were compared with the measured spectra the periods when heating was turned off. During the heating session of the ionosphere, a decrease in the intensity of the microwave radiation of the atmosphere in the ozone line was observed. The lower ionosphere was characterized by intense dynamics. Rapid variations in the amplitude of the scattered signal and the relaxation time of artificial periodic irregularities were observed. The velocity of a regular vertical movement in the D-region of the ionosphere constantly varied direction with average minute values up to $4-5 \mathrm{~m} / \mathrm{s}$. We assume the decrease in the ozone emission spectrum at the altitude of $60 \mathrm{~km}$ can be explained by an increase in the coefficient of electron attachment to oxygen molecules during heating sessions. The lower boundary of the region enriched with atomic oxygen was estimated from the height profile of the API relaxation time.
\end{abstract}

Keywords: mesosphere; ozone; microwave radiometry; lower ionosphere; powerful radio wave; artificial periodic irregularities

\section{Introduction}

Studies of the Earth's lower ionosphere at mesospheric altitudes have been going on for many decades and are still relevant. In this region of the atmosphere, the temperature decreases with altitude to the level of the mesopause, and then increases again. In the physics of the ionosphere, heights of $50-90 \mathrm{~km}$ are the D-region, which is distinguished by a complex ion composition and developed dynamics [1-4]. Ionization of the D-region occurs only in the main in the daytime; in undisturbed conditions in midlatitude ionosphere its electron concentration does not exceed $10^{3} \mathrm{~cm}^{-3}$. The sources of ionization are the radiation of the intense solar line Lyman- $\alpha$, hard X-rays from the Sun and galactic cosmic rays, ultraviolet light, etc. [1,2]. Different sources of ionization prevail at different altitudes. Plasma at mesospheric altitudes contains electrons, positive and negative ions and hydrated cluster ions, which arise as a result of ionization, exchange and recombination processes [5-7]. The concentration of neutral particles is orders of magnitude higher than the concentration of ions and 
electrons. Region D significantly affects the absorption of High Frequency (HF) radio waves and the Ultra Low Frequency (ULF) propagation.

The study of this region of the Earth's atmosphere (lower ionosphere) is carried out by various methods, including the method of partial reflections and the method of incoherent scattering for measuring the electron concentration, high-frequency and medium-frequency radars, lidars for measuring the temperature of the neutral component [8]. One of the promising methods for studying the lower ionosphere is the method of resonant scattering of radio waves by artificial periodic irregularities. The method allows one to determine many parameters of the ionosphere and neutral atmosphere from the characteristics of signals scattered by irregularities [9]. The electron concentration in the D-region is extremely variable even in calm helio- and geophysical conditions. In the lower part of the D-region, the concentration of negative ions exceeds the concentration of electrons. The composition of neutral particles at heights of $50-90 \mathrm{~km}$ is complex and includes many small components that can affect the recombination processes, the processes of electron attachment and detachment. Ozone is one of these constituents. Its reactions with electrons are a source of negative ions of molecular and atomic oxygen $[2,6]$. The altitudinal daytime distribution of ozone has a main stratospheric maximum and a weak local maximum at an altitude of $60 \mathrm{~km}$. A large number of experimental studies of ozone in the Earth's atmosphere have now been published [10-16].

One of the most important problems in the physics of the middle atmosphere is the study of the dependence of the altitude distribution of the ozone concentration on the ionosphere condition at mesospheric altitudes. The altitude distribution of mesospheric ozone was studied under various disturbances in the Earth's atmosphere as during proton events [17] and eclipses [18-22]. In [23] authors was investigated the relationship between natural changes in the total electron content (TEC) in the ionosphere and the content of mesospheric ozone in the altitude range $57-79 \mathrm{~km}$. Based on the results of rocket measurements of the electron concentration in the D-region at the Volgograd station $\left(48.68^{\circ} \mathrm{N} ; 44.35^{\circ} \mathrm{E}\right)$ and a comparing them with the data of simultaneous measurements of ozone concentration from the Solar Mesosphere Explorer (SME) satellite, a correlation between these parameters at heights of 52-60 km during the day and $80 \mathrm{~km}$ at night was found [24].

In addition to the study of natural factors that determine the ozone content in the mesosphere, the anthropogenic impact on ozone is currently being studied [25]. Along with the emission of greenhouse gases, harmful aerosols and chlorine-containing substances into the atmosphere, a large electromagnetic load has an effect on the environment. A large number of radio transmitters emit radio waves of different wavelengths into the Earth's ionosphere. It is important to study the possible consequences of this effect on the ozone content in the mesosphere for understanding the degree of an influence of human activities on the atmosphere. For these studies, the methods of controlled artificial influence on the Earth's ionosphere by powerful HF radio emission are used [26-28] and references therein]. One of the problems is to detect the possible influence of artificial disturbances of the ionospheric plasma on the concentration of mesospheric ozone. The experiments were carried out in 2008, 2009, and 2011 at the SURA midlatitude heating facility $\left(56.15^{\circ} \mathrm{N} ; 46.11^{\circ}\right.$ E) located near Nizhny Novgorod, Russia [29-31]. As a result, such a new physical phenomenon as a decrease in the intensity of microwave radiation of the atmosphere in the ozone line at a frequency of 110,836.04 MHz during a modification of the lower ionosphere was observed. In the first experiments with an effective radiation power of the SURA facility about $100 \mathrm{MW}$, the decrease in the intensity of the atmospheric emission spectrum in the ozone line was about 10\% [30]. In these observations, a microwave spectrometer was used [32]. In subsequent years, the experiments were continued; their results are presented in [29,31]. The method for calculating the altitude profile of ozone concentration from the measured spectra using model altitude profiles of ozone, temperature and pressure [33,34] is contained in [35].

As a result of these studies, it was found that to confirm the effect of artificial high-frequency exposure on mesospheric ozone, it is necessary to carry out an additional study of the lower ionosphere condition, where the main absorption of the energy of a powerful radio wave occurs. The first experiment with simultaneous measurement of the atmospheric emission spectrum in the ozone line 
and diagnostics of the lower ionosphere by API technique was carried out in September 2016. Its results are detailed in [36]. The method of the ionosphere diagnostics based on the resonant scattering of radio waves by the APIs. It allows us to determine many important characteristics of the ionosphere and the neutral atmosphere [9]. In this paper, we present the results of a new experiment on the study of mesospheric ozone and the lower ionosphere condition under the influence of high-frequency heating. The aim of the research is to analyze the results of ozone measurements together with the results of diagnostics of the artificially disturbed lower ionosphere. In these studies, we confirmed previous observations on the decrease of the intensity of atmospheric radiation in the ozone line under the action of powerful radio emission. We obtained new information about the state of the lower ionosphere and the neutral atmosphere using a new research method based on the creation of artificial periodic irregularities of the ionospheric plasma, and we proposed a possible explanation of the observed phenomenon because of changes in the parameters of the D-region under artificial disturbance of the ionosphere.

\section{Methods and Instrumentations}

Investigation of the mesospheric ozone at the mesosphere altitudes and its response to high-frequency impact on the ionospheric plasma was studied using the method of microwave ground-based radiometry to measure the atmospheric radiation spectrum in the ozone line [29-31] and the method of creating of artificial periodic irregularities to diagnose of the lower ionosphere condition and measurement some ionosphere and mesosphere parameters [9]. The first results of these studies are given in [36]. To analyze the ionospheric condition and choose the radiation frequencies of the heating and diagnostics facilities for studying the lower ionosphere by the method of creating the artificial periodic irregularities, we used the data from vertical sounding by the DPS- 4 ( $55.49^{\circ} \mathrm{N} ; 37.29^{\circ}$ E) [37] ionosonde (Institute of Terrestrial Magnetism, Ionosphere, and Radio Wave Propagation of the Russian Academy of Sciences (IZMIRAN) in Troitsk and CADI ionosonde (56.15 $\mathrm{N} ; 46.11^{\circ} \mathrm{E}$ ) located near SURA heating facility (Radiophysical Research Institute, Lobachevsky State University of Nizhny Novgorod). The distance between DPS-4 and CADI ionosondes is about $530 \mathrm{~km}$. We use DPS-4 ionograms for a more complete overview of the condition of the ionosphere near the location of the experiments.

\subsection{Method of the Ground-Based Microwave Radiometry}

The method of microwave ground-based radiometry is based on measuring the rotational emission spectra of small gas constituents of the atmosphere in the millimeter and sub-millimeter wave ranges [38-44]. The advantage of the method over measurements in the infrared and optical wavelengths is its weak dependence on meteorological conditions and the presence of aerosols. Microwave observations of ozone can be performed around the clock. We applied it to study the mesospheric ozone during artificial disturbance of the ionosphere.

In all experiments, identical microwave ozonometers with the same measurement technique were used [32,35]. The ozonometer consists of a heterodyne millimeter wave receiver and a multichannel spectrometer. The receiver was tuned to the fixed frequency at $110,836.04 \mathrm{MHz}$ (the wavelength $\lambda \approx 2.7 \mathrm{~mm}$ ), which corresponds to the transition between the rotational levels of the ozone molecule $\mathrm{O}_{3}$ with the quantum numbers $J=60,6-6_{1,5}$. The receiver input has a unit, which incorporates an antenna (scalar horn) and a switch for calibrating the intensity of the received atmospheric radiation in the ozone line. The spectra of the thermal radiation of the atmosphere are measured using the method of calibration by two "black body" standards, which are kept at the liquid-nitrogen boiling temperature and that of the surrounding air. The directional diagram width of the horn antenna is $5.4^{\circ}$ with respect to the $3 \mathrm{~dB}$ level. The diameter of the range of the atmosphere from which the microwave radiation was recorded was about $6 \mathrm{~km}$ at the altitude of $60 \mathrm{~km}$. This is approximately 2.7 times smaller than the size of the disturbed high-power radio wave D-region (about $16 \mathrm{~km}$ at the level of half the radiation power of the SURA facility). The single-band noise temperature of the receiver is $2500 \mathrm{~K}$ and the 
reception mode in one band is ensured by the below-cutoff filter with direct loss $0.5 \mathrm{~dB}$ and the image channel suppression exceeding $20 \mathrm{~dB}$. The spectrum analyzer consists of 32 filters with the spectral resolution from 1 to $10 \mathrm{MHz}$ and complete analysis band of $240 \mathrm{MHz}$. The device parameters allow one to measure the spectrum of the ozone radiation line with accumulation for $15 \mathrm{~min}$ with an error of no more than $1-2 \%$.

Information on the ozone concentration is contained in the measured spectrum of the integral radio emission of the atmosphere. By inverting the measured spectra, it is possible to obtain data on the vertical distribution of ozone in the atmosphere. Determination of the altitude profile of ozone in the altitude range $20-60 \mathrm{~km}$ by the measured spectrum is performed using the method described in [35]. For this, a method is used to select the parameters of a given model of the altitude distribution of ozone by minimizing the rms differences between the measured spectra and those calculated from the reconstructed ozone profiles [39]. The method is based on a priori information about the shape of the altitudinal ozone distribution. The calculated spectrum was estimated using model dependences of the ozone density [33], pressure, and temperature on the altitude [34].

The criterion for the correctness of the solution to the inverse problem is the best correspondence of the ozone spectral line calculated from the reconstructed profile of the $\mathrm{O}_{3}$ concentration with the original experimental spectrum. The error in determining the height profile of ozone from the measured spectra does not exceed $10-15 \%$ [35].

\subsection{The Method of the Resonance Scattering of Radio Waves on Artificial Periodic Irregularities of the Ionospheric Plasma}

Artificial periodic irregularities were observed in 1975 for the first time in the experiments on studying the influence of high-power radio waves on the sounding radio waves reflected from the ionospheric F-region [45]. Later, APIs were found on other heating facilities [46-51]. In the subsequent experiments, it was proved that artificial periodic irregularities are formed in the field of a high-power standing radio wave resulting from interference of the radio waves, which are incident on the ionosphere and reflected from the latter, in the altitude range from the beginning of the D-region $(50-60 \mathrm{~km})$ to the altitude of reflection of a high-power radio wave. In the D-region, irregularities are formed because of the temperature dependence of the coefficient of the electron attachment to the oxygen molecules during triple collisions [9]. In the E-region, periodic irregularities are created under the action of excess pressure of electron gas which is heated at the standing-wave antinodes. Periodic structure of the temperature and, as a consequence, plasma concentrations with the spatial period that is equal to half-length of a powerful radio wave in the plasma are formed because of no uniform heating of electron gas.

Sounding of the created periodic structure with probe radio waves is a method for its diagnostics. APIs scatters probe radio waves. The in-phase addition of the waves scattered by all the structure irregularities ensures resonant character of scattering. In the case where the heating facility and the detection unit are placed at the same point, the condition of in-phase addition of the waves is ensured by fulfilling the equality of the lengths of the heating and test (sounding) radio waves [9]. Methods for determining many parameters of the ionosphere and neutral atmosphere have been developed. The main ones are the vertical velocity of the ionospheric plasma ant the neutral atmosphere, the turbulent velocity at the height lower the turbopause level, the temperature and the density of the neutral component, the electron density, some parameters of the sporadic-E layer (Es layer) including its ionic composition, an attachment and detachment of electrons to molecules, the ratio of the number of the negative ions to the number of electrons, variation of atomic and excited molecular oxygen and other characteristics of the ionospheric D- and E-regions [9]. At present, many results of experimental studies of the characteristics of the neutral and plasma components of the ionosphere by the API method have been published, obtained using the SURA heating facility to create irregularities. Some of them are presented in [52-65]. 
The method of creating artificial periodic irregularities by powerful radio emission from the SURA facility and diagnostics of the ionosphere and neutral atmosphere describes in detail in [9]. The SURA heating facility, whose transmitters operate for API formation, as a rule, at frequencies of 4.7 and 5.6 MHz has been employed in recent years for detecting periodic irregularities too. We use the receiving part of the partial-reflection unit for recording the scattered signal. Each measurement session lasts $15 \mathrm{~s}$, such that ionospheric modification with the creation of periodic irregularities takes $3 \mathrm{~s}$ while the subsequent $12 \mathrm{~s}$ are used to switch the facility of the pulsed-detector mode emitting sounding radio waves of the same frequency and polarization. The irregularities are created by the extraordinary wave and the wave of the same polarization is used for receiving the scattered signal. The signal scattered by the periodic irregularities at their relaxation stage is recorded when sounding the perturbed region by the pulses with duration of $30 \mu \mathrm{s}$ and a repetition frequency of $50 \mathrm{~Hz}$. The signals scattered by artificial irregularities are amplified by a receiver with the pass band $70 \mathrm{kHz}$, digitized by a 12-bit analog-to-digit converter, and recorded in the interval of operating altitudes $0-750 \mathrm{~km}$ in the form of quadrature components with altitude steps 0.7 or $1.4 \mathrm{~km}$. As a result, the altitude profiles of the amplitude and phase of the scattered signal are obtained. The relaxation time of the artificial irregularities is determined after the heating is over when the scattered-signal amplitude decreases by a factor of e, while the signal-phase variation determines the velocity of the vertical motion of plasma [9].

The combination of two methods for studying the atmospheric-radiation spectra in the ozone line during artificial ionospheric modification by high-frequency radio waves from the SURA facility was for the first time experimentally realized in September 2016. The results of these studies are presented in [36].

\section{Experiments and Results}

\subsection{Microwave Measurements of the Ozone Spectrum}

Experiments with measuring the emission spectrum of the atmosphere in the ozone line were carried out from 10 to 12 September 2019. The SURA heating facility radiated into the zenith an extraordinary radio wave with a frequency of $4.7 \mathrm{MHz}$ from 10:01 to 18:01 with an effective power about $100 \mathrm{MW}$ for $30 \mathrm{~min}$ on 11-12 September 2019. The antenna of a mobile microwave ozonometer was oriented in the same direction. In two days, thirteen sessions of long 30-min exposure to the ionosphere were carried out. In the next $30 \mathrm{~min}$, the SURA facility was switched to the operating mode for the API creation and diagnosis. The microwave ozonometer operated at a frequency of $110,836.04 \mathrm{MHz}$ in the mode of continuous measurement of the radiation intensity in the ozone line. The measurement of each spectrum lasted $15 \mathrm{~min}$, so that two ozone emission spectra were obtained in each heating interval of the ionosphere and during heating off. Thus, it was possible to compare the spectra of ozone during artificial disturbance of the ionosphere and after its termination. In addition to variations in the mesospheric ozone caused by the heating of the lower ionosphere by powerful HF radio waves, day-to-night measurements natural background variations in the ozone emission of the middle atmosphere were carried out. The most known natural ozone variations are its daily variations at altitudes of over $40 \mathrm{~km}$ associated with sunrise and sunset.

It was observed in the experiment that each time the heating facility was turned on, the intensity of the measured atmospheric radiation in the ozone line at a frequency of 110,836.04 MHz decreased. This result was obtained in all experiments to study the possible effect of ionospheric heating on mesospheric ozone [29-31,36].

Figure 1 shows the change in the ozone spectrum during artificial disturbance of the ionosphere for one of the heating sessions 11 September 2019 (left panel) and 30 September 2016 (right panel, it is taken from [36]. In the left panel of the Figure 1 the spectrum of atmospheric radiation in the ozone line obtained on 11 September 2019 during the heating session at 09:31 (red marks) and the pause session at 10:01 (black marks), depending on the frequency of detuning from the operating frequency of $110,836.04 \mathrm{MHz}$ of the ozonometer. The spectrum for the night session 02:29-02:58 (blue marks) is 
also shown. For clarity, the spectra are shifted along the frequency axis to the right and left by $100 \mathrm{MHz}$. The vertical bars show the standard deviation when calculating the averaged spectrum. Solid curves (red, blue and black) show the spectra calculated using the vertical ozone distributions. The spectra were obtained for the altitude interval $22-60 \mathrm{~km}$. The spectrum intensity is presented in units of the optical thickness.
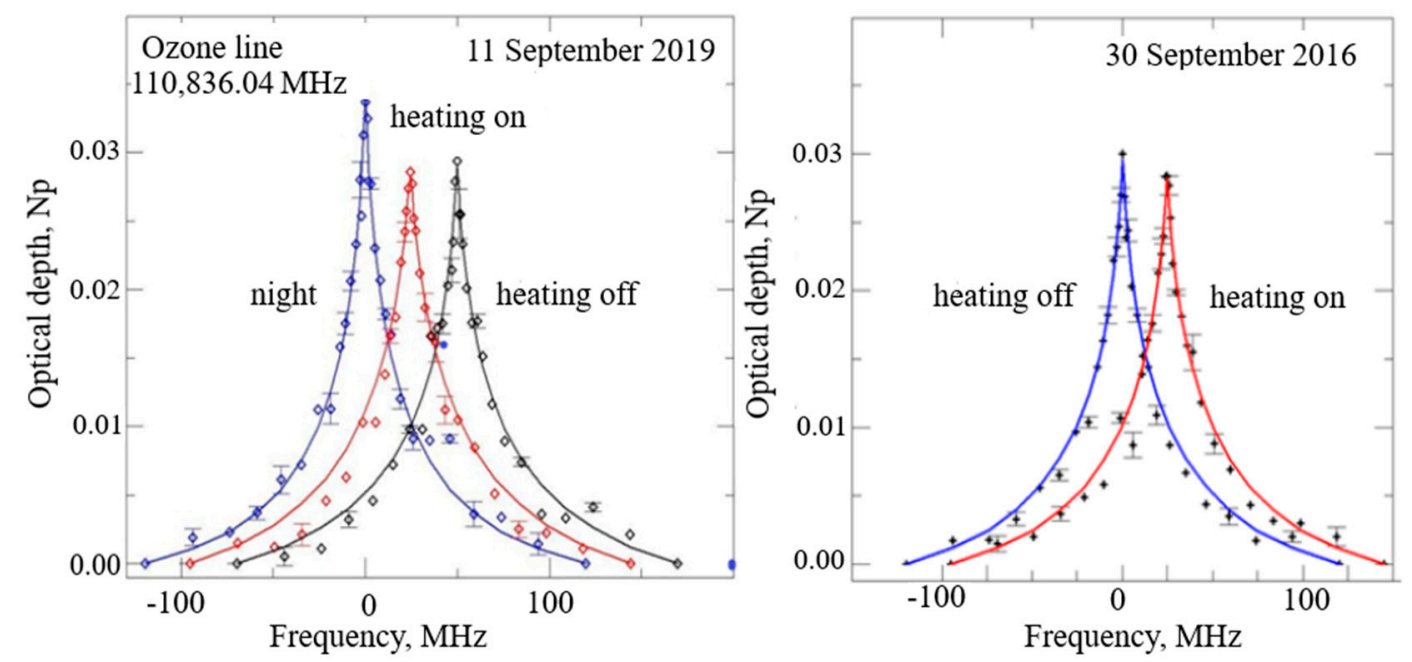

Figure 1. Modification of the ozone spectrum during artificial disturbance of the ionosphere for one of the heating sessions in 11 September 2019 (left panel) and 30 September 2019 (right panel). On the left panel red and black circles show the spectrum values during the heating and pause sessions. Blue circles refer to nighttime ozone spectrum measurements. Solid curves (red, blue and black) on the left panel show the spectra calculated using the vertical ozone distributions. On the right panel red and blue lines show ozone spectrum measured during the heating and pause sessions respectively.

In Figure 1 the difference between the intensities of the spectra for 11 September 2019 for an artificially disturbed ionosphere from its undisturbed state is 3\%, and the difference between night and day is $14 \%$. We calculated the value of total ozone content in an atmospheric column in the altitude range from 22 to $66 \mathrm{~km}$. In observations in 11 September 2019 we obtained values $X=(145.0 \pm 2.1)$ DU and $X=(144.96 \pm 3.1)$ DU for the pause and heating sessions, respectively. The values of $X$ were obtained from an estimating the vertical distribution of ozone for each measured spectrum.

We also provide an example of the ozone spectrum for 30 September 2019 (Figure 1, right panel). The example is adopted from the work [36]. The vertical profiles of ozone were, in turn, determined using the spectra which were measured by the method described in $[19,35]$. The values of total ozone content $X=(143.8 \pm 2.1) \mathrm{DU}$ and $X=(142.6 \pm 2.3)$ DU obtained for the pause and heating periods, respectively. The values of $X$ were obtained from estimating the vertical distribution of ozone for each measured spectrum. Obviously the $\mathrm{X}$ values for the perturbed and unperturbed states only slightly differ. This is indicative of the fact that the ozone content in the measurement periods was mainly determined by the unperturbed stratosphere (up to $50 \mathrm{~km}$ ), which contains the main amount of ozone compared with mesosphere. It is well known that the ozone content in mesosphere is several Dobson units and in the region of $22-60 \mathrm{~km}$ it is about $140 \mathrm{DU}$.

The main result of measurements is a decrease in the intensity of atmospheric radiation in the ozone line during heating by an average of $(7 \pm 1) \%$ relative to the radiation intensity during a pause in the operation of the facility. For individual sessions, the decrease was $9 \%$. The difference between the spectra obtained during heating on and heating off sessions was small. The decrease in ozone concentration at the altitude of $60 \mathrm{~km}$ was $12 \%$. The ozone concentration was calculated by the method presented in [19]. In some sessions, the reduction was up to $20 \%$. Note that the relative value of the decrease in the ozone-line intensity during ionospheric heating is small and is in some cases comparable with the measurement error. However, the differences in the spectra during the heating on 
and heating off sessions are considered significant, since they were observed in all experiments on studying the ozone spectrum in an artificially disturbed ionosphere [29-31,36].

Figure 2 shows ozone density variations at the altitude of $60 \mathrm{~km}$ for three days during experiments at the SURA facility in September 2019, of which ozone observations with the disturbance of the ionosphere were carried out on 11 and 12 September 2019.

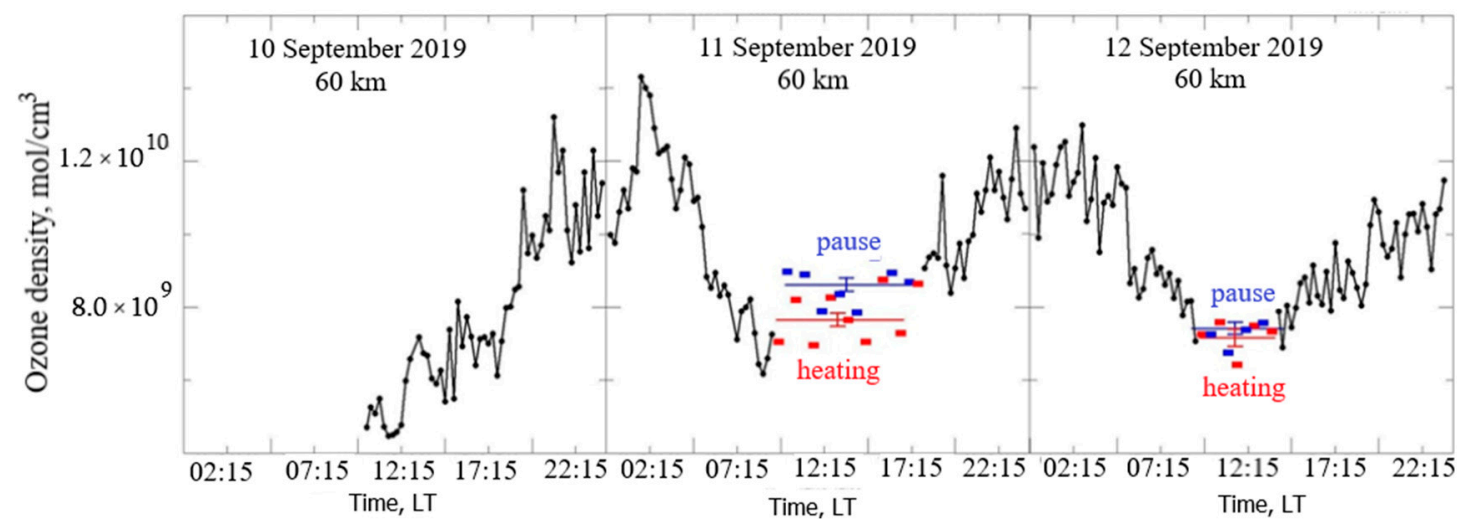

Figure 2. Temporal variations of the ozone density during from 11 September 2019 to 12 September 2019. Each black dot is obtained for the corresponding intensity of the ozone spectral line measured with an accumulation time of $15 \mathrm{~min}$. Red and blue short strips show ozone density values averaged over each heating and pause session.

In Figure 2 each black dot is obtained for the corresponding intensity of the ozone spectral line measured with an accumulation time of $15 \mathrm{~min}$. Red and blue strips show ozone density values averaged over each heating and pause session. Of these, each black dot (except for the averaged values for the intervals of heating on and off) was also obtained for the corresponding intensity of the ozone spectral line. The horizontal lines show the ozone density values averaged over all heating sessions (red line) and pauses (blue line). In order not to clutter up the figure, the error in determining the ozone density, which is no more than 10\% does not show in the graph [29-31,36].

Figure 2 clearly shows the correlation of ozone density variations with heating periods. The following features of ozone density variations are also visible.

(1) A significant difference in the results on the change in the ozone density during the heating time for September 11 and 12, both in the average values for the whole day and for individual sessions. In September 12, changes in the ozone density during heating turned on to be on average very small and amounted to no more than $3 \%$. On September 11, they were equal to $12 \%$ on average, and in some sessions they increased up to $20 \%$.

(2) Relatively fast and deep variations in the ozone density are clearly visible, ranging from 30 to $50 \%$. They are not related to the heating of the ionosphere, and are probably largely due to the dynamics of this region of the mesosphere, including winds with variations of the direction and magnitude of the velocity, developed atmospheric turbulence, a propagation of atmospheric waves, changes in the composition of the mesosphere at these altitudes over time, and other factors.

(3) One can see wavelike variations in the ozone density with a quasi-period from $45 \mathrm{~min}$ to $3 \mathrm{~h}$ or more.

(4) Daily variations in the ozone density are visible, with noticeable differences occurring at night and during the day, which corresponds to the usually observed daily variation of ozone density with an excess of nighttime concentration values over daytime; the average amplitude of the daily change in the density of atmospheric ozone was about $40 \%$.

(5) The change in the amplitude of the diurnal variation on different days of observations is clearly noticeable, which can be explained by the influence of natural dynamic processes on the ozone in the mesosphere. 


\subsection{Diagnostics of the Lower Ionosphere Using the Method of Artificial Periodic Irregularities}

To study the perturbations of the ionized component at the heights of the mesosphere and lower thermosphere, we used the method of resonant scattering of radio waves (the API technique). In contrast to the experiments carried out by the authors [29-31], where high-power radio waves were emitted with an inclination of 12 degrees to South of the vertical at a frequency of $4.3 \mathrm{MHz}$, in our experiments in 2016 and 2019 transmitters of the SURA heating facility always emitted to zenith an extraordinary wave at the frequency of $4.7 \mathrm{MHz}$ with a periodicity of $60 \mathrm{~min}$. Of these, a powerful radio wave was emitted for $30 \mathrm{~min}$ to disturb the ionosphere. In the next $30 \mathrm{~min}$, transmitters of the SURA facility operated in short cycles of $15 \mathrm{~s}$. In the first $3 \mathrm{~s}$ of the cycle APIs were generated, and in the next $12 \mathrm{~s}$, after the end of heating at the stage of a disappearance (relaxation) of irregularities a pulsed sounding of the ionosphere with a frequency of $50 \mathrm{~Hz}$ was carried out. This mode of high-power radio wave emission for APIs creating and probe radio wave for measuring the characteristics of signals scattered by artificial irregularities did not affect the measurement of the atmospheric emission spectrum in the ozone line and did not lead to an increase its measurement errors.

The technique for measuring signals scattered by APIs has been well developed by us and applied in a large number of studies of the ionosphere and the neutral atmosphere by this method. Measurement of the amplitude and phase of the scattered signal at the API relaxation stage and the relaxation time of irregularities, make it possible to determine many important parameters of the ionized and neutral components of the Earth's atmosphere at the heights of the mesosphere and lower thermosphere [9,52-64].

\subsubsection{Scattered Signal Characteristics and the Ionosphere Condition}

Figures 3 and 4 show the dependences of the scattered signal amplitude on the virtual height and the time on the days of ozone measurements on 11 and 12 September 2019. Virtual height is the apparent height of the reflection of a radio wave during vertical sounding of the ionosphere. It is defined as the distance that an electromagnetic wave passes in a vacuum in a time equal to half the propagation time of the probe signal. Further, it is recalculated to the true height on the base the ionogram of thr vertical sounding, measured by ionosonde. The Figures show signals both reflected from the ionosphere (virtual heights above $300 \mathrm{~km}$ ) and signals scattered by artificial periodic irregularities in the height range of $60-130 \mathrm{~km}$. For presentation in this form, the signal amplitude was averaged for every $12 \mathrm{~s}$ from the beginning of its recording. In Figures 3 and 4 , red vertical stripes show 30-min intervals of the SURA facility was turned on. As a rule, in the first minute of a 30-min interval (end of the pause, or start of the heating), the CADI digital ionosonde recorded an ionogram.

We present the result of recording the amplitudes of ionospheric signals in the entire height range from 0 to $700 \mathrm{~km}$ in order to clearly demonstrate the effect of the state of the ionosphere on the reflected and scattered signals.

Figures 3 and 4 show that in the altitude interval $60-80 \mathrm{~km}$, signals scattered by artificial irregularities were observed in the D-region. Their amplitude increased with time, the region of the heights of these signals expanded towards the end of observations. Throughout the day, a stable signals scattered by the APIs in the E-region were observed at heights range of 90-120 km. Sometimes, the lower boundary of this region decreased with time to almost $80 \mathrm{~km}$. The amplitude of the signal scattered by irregularities in the $\mathrm{E}$ region also increased with time. 


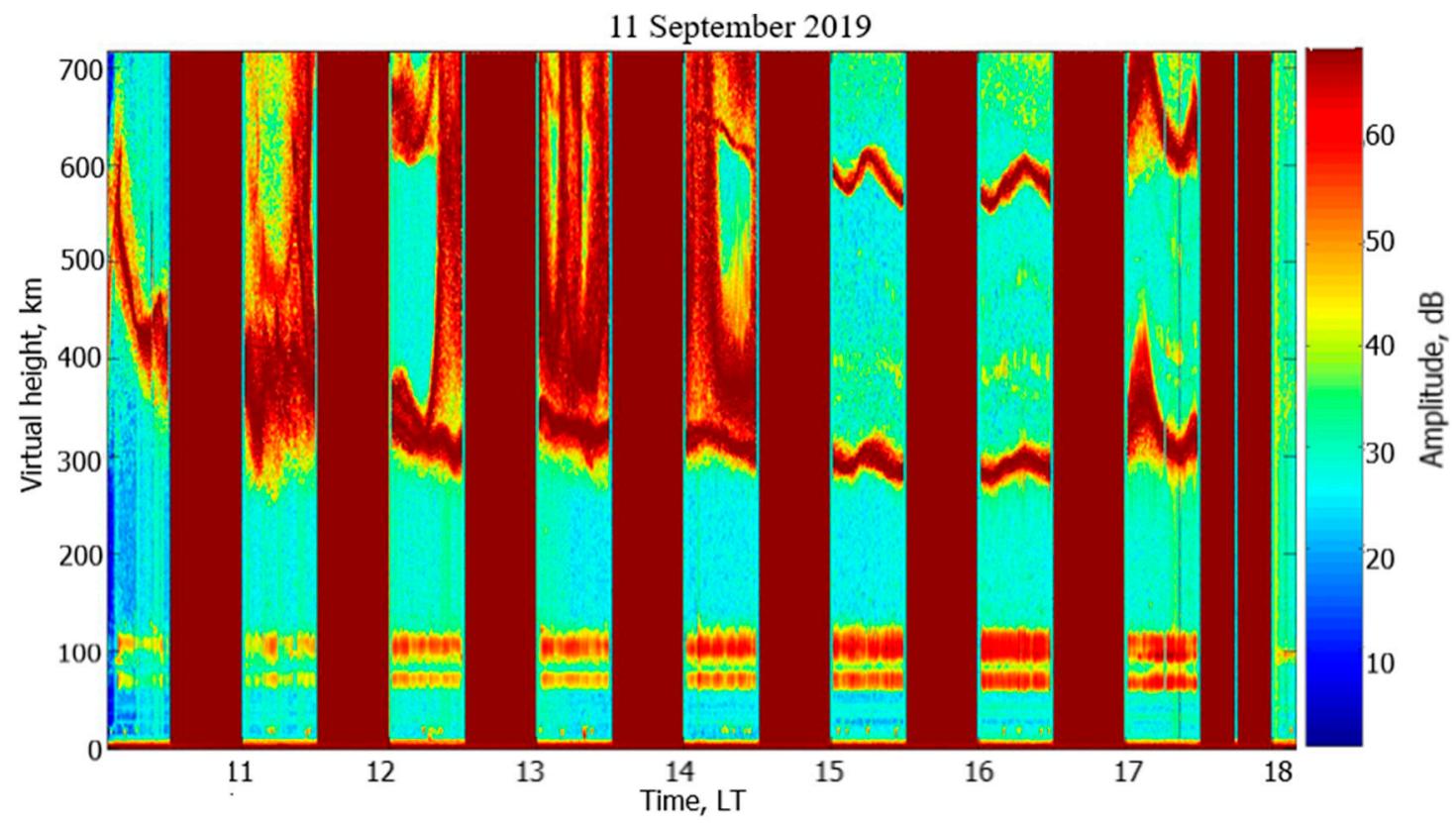

Figure 3. The virtual height-time dependence of the scattered-signal amplitude in 11 September 2019.

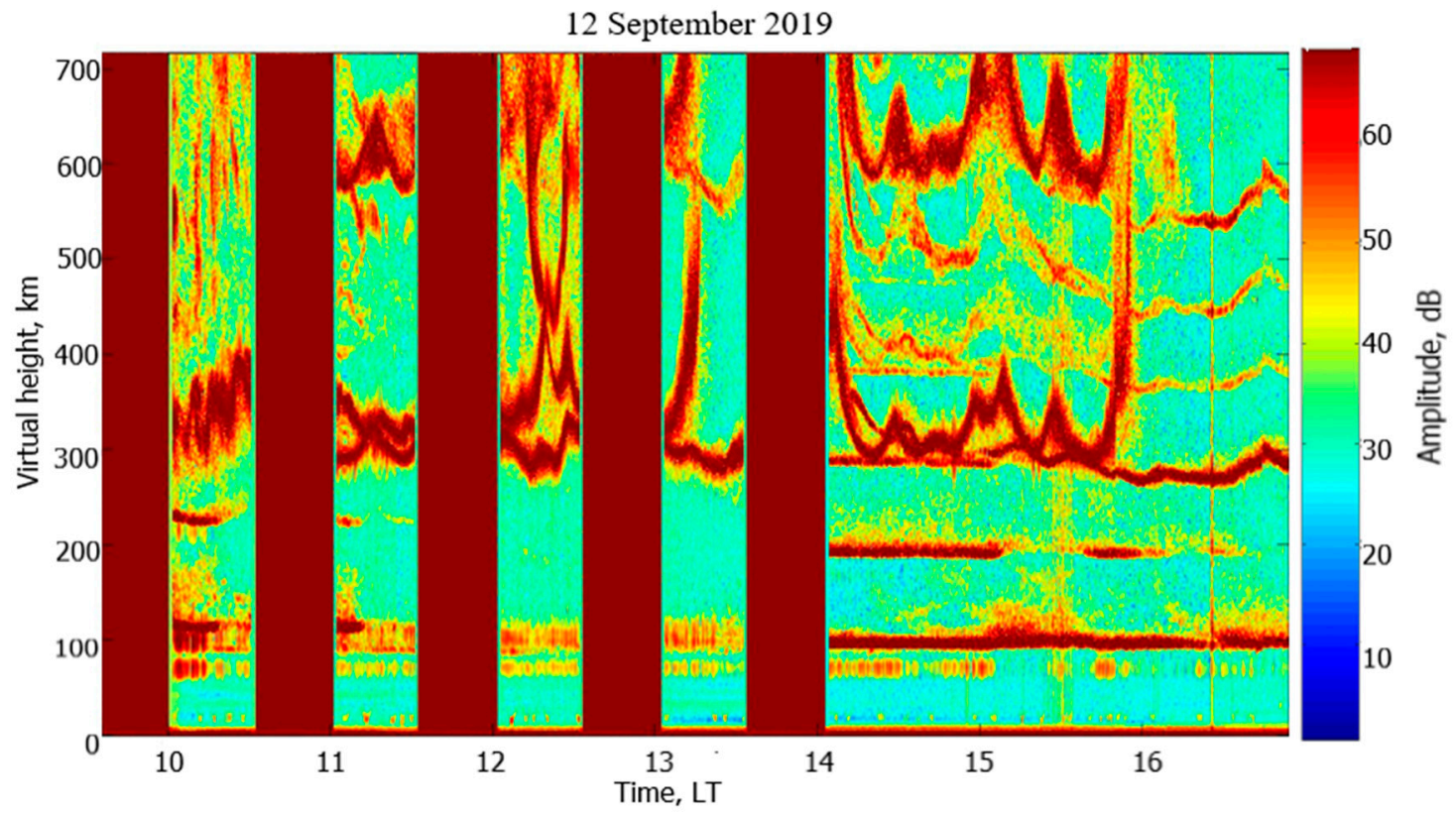

Figure 4. The virtual height-time dependence of the scattered-signal amplitude in 12 September 2019.

In Figure 3, in the region of effective heights above $300 \mathrm{~km}$, one can see typical signals specularly reflected in the $\mathrm{F}$ region. In the first hours of observations, a gradual decrease in the height of the reflection of the sounding extraordinary wave is seen. An ordinary wave mostly passed through the ionosphere without the reflection. A wave-like change in the reflection height is observed. It is especially noticeable in the first $3 \mathrm{~h}$ of observations and it is caused by the propagation of atmospheric waves. The frequency of $4.7 \mathrm{MHz}$ of an ordinary wave in most sessions was close to the critical frequency of the F-layer of the ionosphere (up to $15 \mathrm{~h}$ ) or exceeded it (after $15 \mathrm{~h}$ ). Signals at an altitude of more than $600 \mathrm{~km}$ are the second reflection (multiple) of the extraordinary component of the sounding wave from the ionosphere. 
We note one feature of the vertical dependence of the scattered signal amplitude, which is clearly visible in Figures 3 and 4 . This is the absence of scattered signals in the $80-90 \mathrm{~km}$ altitude range. We'll discuss this observation below.

Another condition of the ionosphere was on 12 September 2019. One can see on Figure 4 that at the beginning of observations from 10:00 to 11:20 LT, a semitransparent sporadic E-layer $\left(E_{s}\right)$ was formed at an altitude of $120 \mathrm{~km}$. Its critical frequency was 3.5-4.0 MHz. A significant part of the powerful radio wave that disturbed the ionosphere was reflected from the $E_{s}$-layer. At the same time, intensive scattered signals from the APIs were observed in the D- and E-regions. Over time, they became less intense. The range of heights occupied by artificial irregularities in the D-region narrowed. Between 15:00 and 15:30 LT, a diffuse reflection appeared from the upper boundary of the $\mathrm{E}_{\mathrm{s}}$-layer. The $\mathrm{E}_{\mathrm{s}}$-layer gradually disappeared and reappeared after $14 \mathrm{~h} \mathrm{LT}$ at an altitude of 100-110 km. Numerous multiple reflections of the probing radio wave from it were observed. We do not assert that the sporadic-E layer appeared as a result of the impact of the powerful radio emission from the SURA facility on the ionospheric plasma, but such a development of events is not excluded. Wavelike variations in the height of the signal reflection in the F-region with a period of 5-10 min were observed in the pauses between the intervals of the heating of the ionosphere.

From the time-altitude signal amplitude dependences scattered PIT shown in Figures 3 and 4 shows that 11 and 12 September Status ionosphere was different that, in particular, manifested a difference in the behavior of API scattered signals.

The geomagnetic and heliophysical conditions were calm these days. According to [37] data on September 10-11, geomagnetic activity was low. The local k-index of geomagnetic activity varied within the range of $k=1-2$, increasing to $k=3$ from 18:00 to 21:00. At this time, the observations were already over. During the period of ozone observations, the Sun was calm, there were no sunspots. From the analysis of ionograms obtained by the CADI digital ionosonde it can be seen that a sporadic layer $E_{s}$ of the high (h) or peak-like (c) type existed at an altitude of about $100 \mathrm{~km}$ almost all day and most of the night. The critical frequency of the F-layer during the hours of artificial impact on the ionosphere varied from 4.2 to $5 \mathrm{MHz}$. On another day of ozone measurements, September 12, with the diagnostics of the ionosphere by the API technique, the local index of the geomagnetic activity was equal to $k=1-2$ with and it increased to $\mathrm{k}=3$ from 12 to $15 \mathrm{~h}$ LT. That is, part of the ozone observations on 12 September 2019 (the last two heating sessions) took place under a weak geomagnetic disturbance. The conditions for ozone measurements were favorable. The weather was clear, measured tropospheric attenuation was no more than $0.4 \mathrm{~Np}$. Attenuation values are determined from measured brightness temperatures from spectral channels. To determine tropospheric attenuation, the channel that is farthest from the channel with the ozone line resonance is used [36].

\subsubsection{API Scattered Signal Amplitude and Relaxation Time}

The altitude dependence of the relaxation time of the scattered signal is the basis for determining many parameters of the ionosphere and neutral atmosphere. Figure 5 shows the height dependences of the amplitude A (right curves) and relaxation time $\tau$ (left curves) of the API scattered signal in the D-region (60-80 km) and in the E-region (90-120 km) for four sessions of the API recording with a duration of one minute. Let us note the main features of the altitude profiles of $\tau(\mathrm{h})$ and $\mathrm{A}(\mathrm{h})$. For all profiles, the maximum amplitude near $100 \mathrm{~km}$ corresponds to the maximum of the electron density in the E-region. A sharp decrease in the signal amplitude at the height about $75 \mathrm{~km}$ was observed. It can be seen that there is no scattered signal in the range of $80-90 \mathrm{~km}$. Accordingly, the relaxation time at these heights has not been determined. 
11 September 2019
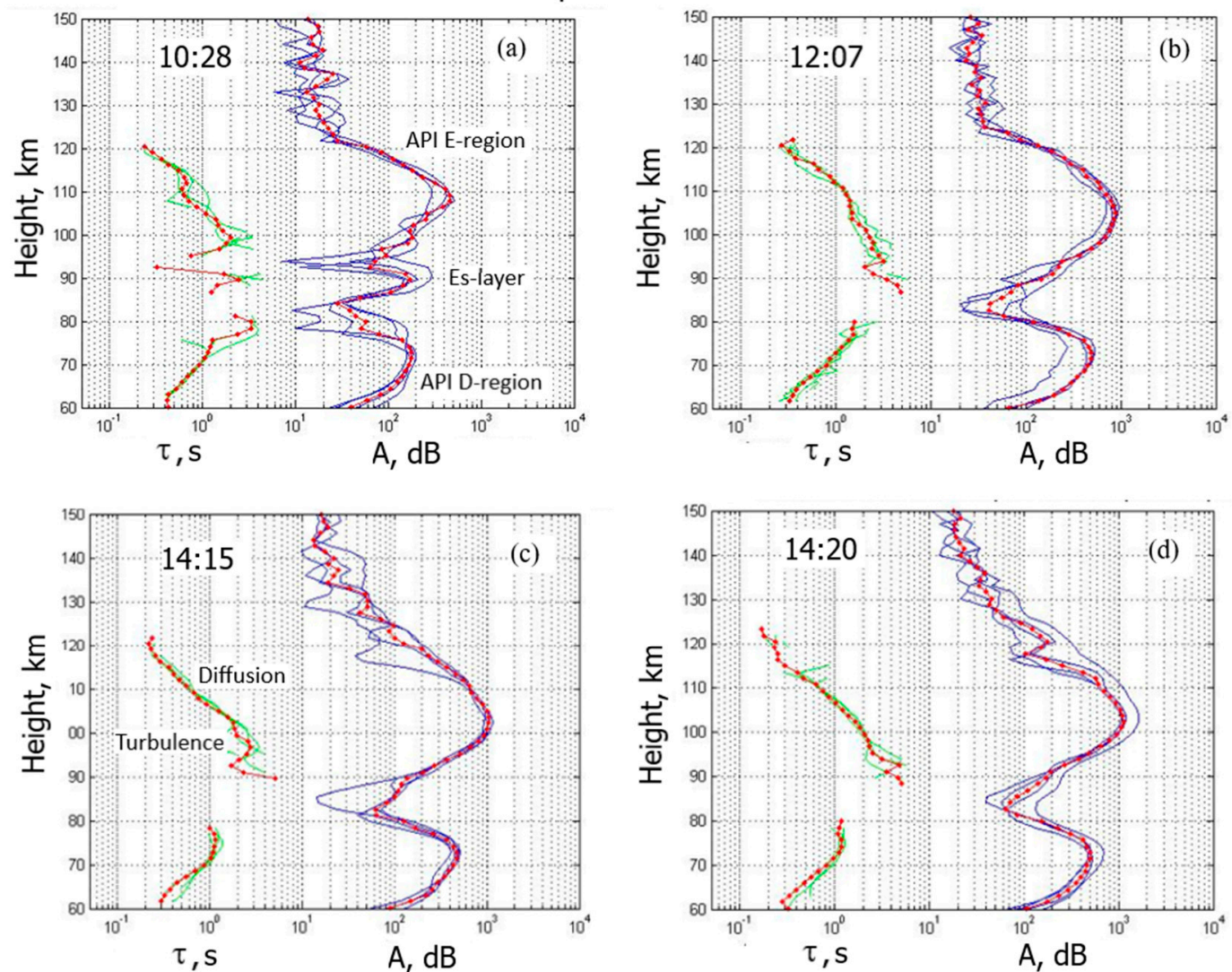

Figure 5. Height dependences of the amplitude A (right curves) and relaxation time $\tau$ (left curves) of the API scattered signal in the D-region $(\mathrm{h}=60-80 \mathrm{~km})$ and in the E-region $(\mathrm{h}=90-120 \mathrm{~km})$ for four sessions of the API recording with a duration of one minute. Blue curves for amplitude and green curves for relaxation time show the dependences $A(h)$ and $\tau(h)$, obtained in every $15 \mathrm{~s}$ of the API recording. Red curves with dots show the altitude dependences of the amplitude and relaxation time averaged over one minute. Session time is shown in the figures in the format hours: minutes (a) 10:28, (b) 12:07, (c) 14:15, (d) 14:20.

In Figure 5a, the local amplitude maximum at an altitude of $90 \mathrm{~km}$ is caused by the emergence of a sporadic-E layer. Heavy positive metal ions with masses different from the "normal" atmospheric $\mathrm{NO}^{+}$and $\mathrm{O}_{2}^{+}$ions may be present in the sporadic-E layer. The API relaxation time is proportional to the ion mass; therefore, it increases at the height of the $E_{s}$-layer $[9,58,60,63]$. In Figure $5 c, d$, the dependence $\tau(h)$ is, on average, well approximated by an exponential function and corresponds to the diffusional nature of relaxation. This allows us to determine the temperature $\mathrm{T}$ and the density $\rho$ of the neutral atmosphere $[9,59,62]$. In Figure $5 \mathrm{a}, \mathrm{b}$, the $\tau(\mathrm{h})$ curves are less "smooth", such data are usually not used to determine $T$ and $\rho$. At altitudes less than $95-100 \mathrm{~km}$, the decrease in relaxation time is due to the influence of atmospheric turbulence, which destroys APIs [9,61,64].

In observations on 12 September 2019, the characteristics of the signals scattered by the API differed from the previous day, although, in general, the main features of the altitude profiles of the amplitude and relaxation time remained the same.

Figure 6 shows the height dependences of the amplitude and relaxation time for 12 September 2019. 
12 September 2019
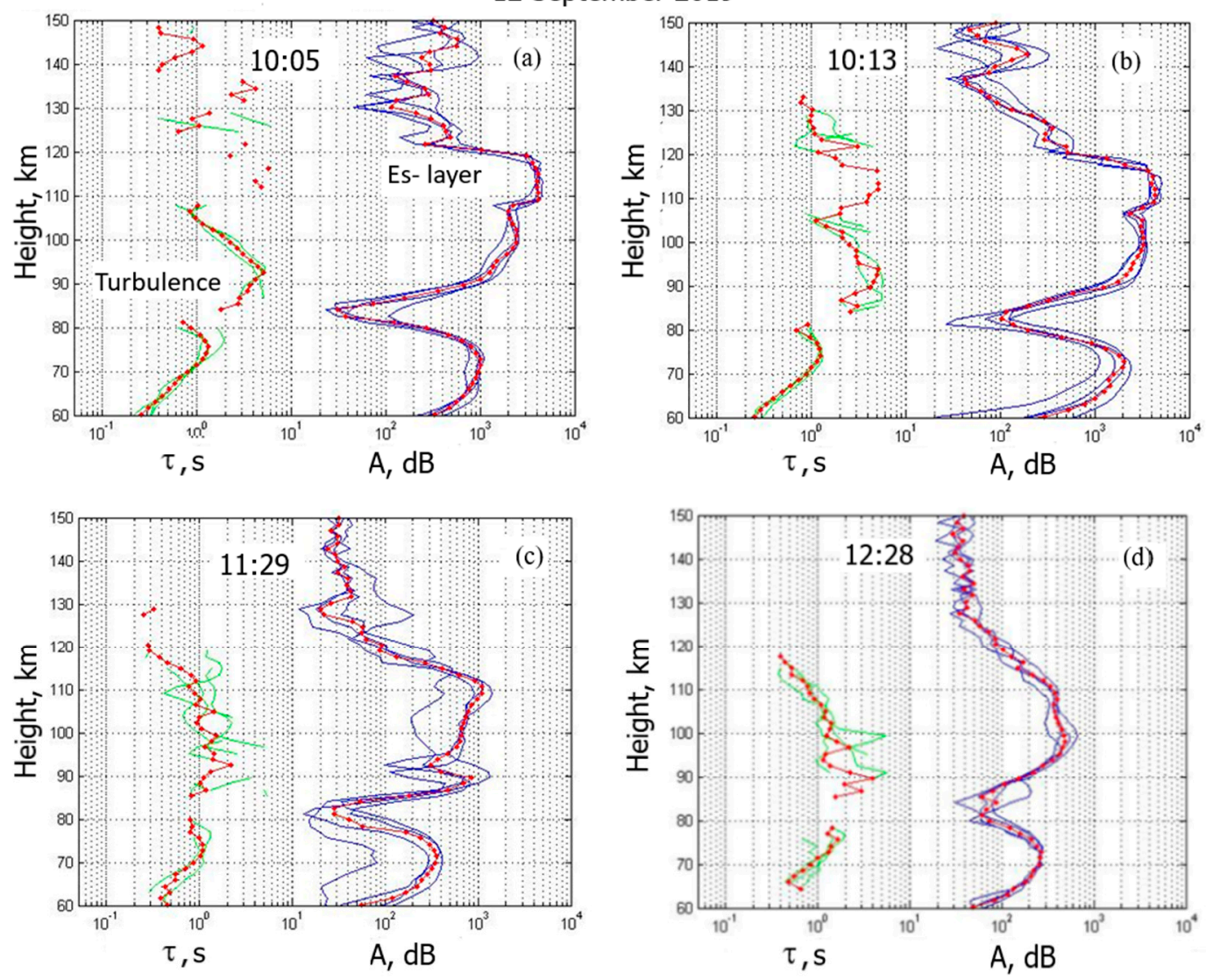

Figure 6. Height dependences of the amplitude A(h) (right curves) and relaxation time $\tau(\mathrm{h})$ (left curves) of the API scattered signal in the D-region $(\mathrm{h}=60-80 \mathrm{~km})$ and in the E-region $(\mathrm{h}=90-120 \mathrm{~km})$ for four sessions of the API recording with a duration of one minute on 12 September 2019. The designations are the same as in Figure 5. Session time is shown in the figures in the format hours: minutes (a) 10:05, (b) 10:13, (c) 11:29, (d) 2:28.

Figure $6 \mathrm{a}, \mathrm{b}$ show a sporadic E layer at an altitude of 100-120 km. At the height of the layer maximum, the amplitude of the scattered signal exceeded the dynamic range of the receiving equipment. Below an altitude of $95 \mathrm{~km}$, turbulence begins to affect the amplitude and relaxation time of the API scattered signal. In Figure $6 \mathrm{c}$ one can see another sporadic-E layer at an altitude of $90 \mathrm{~km}$. In this session, an increase in the relaxation time due to a sporadic layer competes with a decrease in $\tau(\mathrm{h})$ due to the influence of atmospheric turbulence.

As we noted above, there is a region of heights in which there is no scattered signal (Figures 3 and 4). This is also clearly seen in the altitude dependences of the amplitude $\mathrm{A}(\mathrm{h})$ and relaxation time $\tau(\mathrm{h})$ in Figures 5 and 6 . In the range heights of $h=80-90 \mathrm{~km}$ on 11 September 2019 and $\mathrm{h}=80-85 \mathrm{~km}$ on 12 September 2019, the signal amplitude decreased to the level of natural noise and as a result, there relaxation time was not obtained.

Thus, studies of the lower ionosphere, carried out by the method of resonant scattering of probe radio waves at the APIs, show that the ionosphere at mesospheric altitudes is highly variable. Many natural factors affect the characteristics of the signal scattered by irregularities. We draw attention to the fact that although irregularities are created in the ionosphere by the powerful radio emission by the SURA facility we analyze the state of the ionosphere after the end of heating, when the temperature of electrons, which increases when acting on the ionosphere, returns to unperturbed condition within a very short time with value of $10^{-3} \mathrm{~s}$. 


\section{Characteristics of the Ionosphere and Neutral Atmosphere}

The altitude dependences of the scattered signal amplitude in the D- and E-regions shown in Figures 5 and 6 are due to different physical processes that create APIs and affect their relaxation. In the E-region APIs are formed under the action of excess pressure of the electron gas heated in the antinodes of the standing wave. At altitudes of $90-120 \mathrm{~km}$, the API relaxation occurs under the influence of the ambipolar diffusion. The relaxation time is determined by the following expression:

$$
\tau=\frac{1}{K^{2} D}=\frac{M_{i} v_{i m}}{k_{b}\left(T_{e o}+T_{i o}\right) K^{2}}=\frac{M_{i} v_{i m}}{2 k_{b} T K^{2}}
$$

where $k_{b}$ is the Boltzmann constant, $K=4 \pi / \lambda$ is the wavenumber of the standing wave, $\lambda=\lambda_{0} / \mathrm{n}$ is the wavelength in the propagation medium, $\mathrm{n}$ is the refractive index, $\mathrm{D}$ is the ambipolar diffusion coefficient, $\mathrm{M}_{\mathrm{i}}$ is the molecular mass of the ion, $\mathrm{T}_{\mathrm{e} 0}$ and $\mathrm{T}_{\mathrm{i} 0}$ are the unperturbed electron and ion temperatures, and $v_{\mathrm{im}}$ is the frequency of collisions between ions and neutral molecules. At the mesosphere and the lower thermosphere heights $T_{e 0}=T_{i 0}=T$, where $T$ is the temperature of the neutral component. In the mid-latitude ionosphere, this equality can be fulfilled up to altitudes of $120-130 \mathrm{~km}$. The above expression for $\tau$ underlies the determination of many parameters of the lower ionosphere [9]. The measured phase $\Phi$ of the scattered signal is used to determine the velocity of vertical plasma motion as:

$$
V=\frac{\lambda}{4 \pi} \cdot \frac{d \Phi}{d t}=\frac{c n}{4 \pi f} \cdot \frac{\Delta \Phi}{\Delta t}
$$

where $\mathrm{c}$ is the light velocity, $\mathrm{n}$ is the refractive index of a powerful (and probe radio wave), and $\mathrm{f}$ is the frequency of powerful radio emission that creates irregularities. Note that positive vertical velocity values correspond to downward movement. At the heights of the mesosphere and lower thermosphere, the plasma velocity $\mathrm{V}$ is equal to the velocity of the neutral component.

In the D-region, irregularities are formed because of the temperature dependence of the coefficient of the electron attachment to the oxygen molecules during triple collisions [9]. The relaxation time of irregularities in the D-region depends on the electron attachment and detachment coefficients as $\tau=(\beta+\gamma)^{-1}$, where $\beta$ and $\gamma$ are the electron attachment coefficients to molecular oxygen and detachment coefficients from negative ion, respectively. In [9,53-56] it is shown that in the D-region the height dependences of the amplitude $\mathrm{A}(\mathrm{h})$ and relaxation time $\tau(\mathrm{h})$ in the lower part depend on the density of the atmosphere and the concentration of atomic oxygen, and in the upper part only on the concentration of atomic oxygen. In this case, the $\mathrm{A}(\mathrm{h})$ profile also depends on the electron density profile. Modeling carried out in [53-56] showed that a sharp decrease $\tau$ at altitudes of $75 \mathrm{~km}$ and above is due to an increase in the concentration of atomic oxygen, which leads to an increase in the rate of detachment of electrons from negative ions and a corresponding decrease of the relaxation time. At the same time, there is a sharp drop in the concentration of negative ions and, in fact, the APIs formation stops due to the attachment of electrons to oxygen molecules. Thus, from the height in the lower part of the D-region, at which the amplitude of the API scattered signal begins to decrease and the API formation stops, one can estimate the height of the lower boundary of the range enriched of atomic oxygen.

Figure 7 shows the temporal variation of the height in the mesosphere $\mathrm{h}_{1}$, at which the amplitude of the scattered signal began to decrease sharply (black dots) and the height $h_{2}$, at which the scattered signal disappears completely (red dots). These heights were determined from height profiles of amplitude and relaxation time, similar to those shown in Figures 5 and 6 . According to $[9,53]$, the height $h_{1}$ can be considered as the height of the lower boundary of the region enriched in atomic oxygen. On can see that most of the $h_{1}$ values there are at 74,76 and $77 \mathrm{~km}$. In this respect, the most interesting is the segment between sample numbers 110 and 190. The altitude at which the scattered signal reappears varies mainly within the range of $79-82 \mathrm{~km}$. The altitude at which the scattered signal disappears completely varies mainly within the range of $79-82 \mathrm{~km}$. Scattered API signal usually 
reappears at an altitude of $90 \mathrm{~km}$, when irregularities are formed due to plasma redistribution. Sessions when the scattered signal exists below $90 \mathrm{~km}$ correspond to Figures $5 \mathrm{a}$ and $6 \mathrm{c}$, when a sporadic-E layer develops near this height.

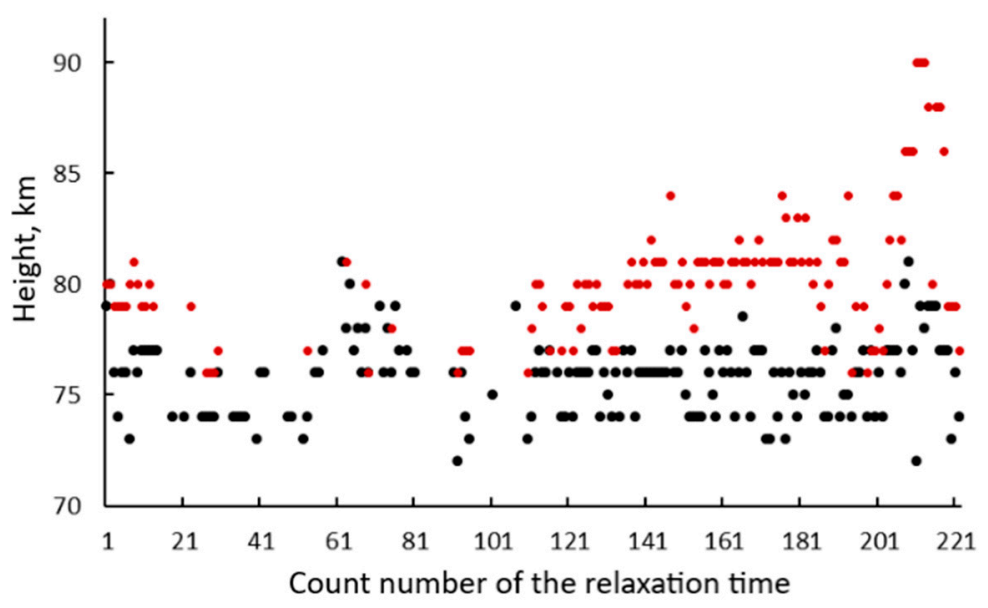

Figure 7. The temporal variation of the height in the mesosphere $\mathrm{h}_{1}$, at which the amplitude of the scattered signal began to decrease sharply (black dots) and the height $\mathrm{h}_{2}$, at which the scattered signal disappears completely (red dots) on 11 September 2019.

There are some more examples of determining the parameters of the mesosphere. Figures 8 and 9 show the results of determining the relaxation time of the API scattered signal and the rate of vertical movement for each 30-min session (pause) after the end of heating on 11 and 12 September 2019.

Figure 8a shows the time dependence of the relaxation time (averaging over $1 \mathrm{~min}$ ) and in Figure $8 \mathrm{~b}$ there is the time dependence of the vertical velocity (averaging over $5 \mathrm{~min}$ ) for heights of 65.8 (circles) and $75.6 \mathrm{~km}$ (points) for September 11. In the D-region, the relaxation time varied in the range of $0.5-1.7 \mathrm{~s}$ with an average of $0.5 \mathrm{~s}$ at an altitude of $65.8 \mathrm{~km}$ and $1.2 \mathrm{~s}$ at an altitude of $75.6 \mathrm{~km}$. This corresponds to the mechanism of formation and relaxation of API, due to the dependence of the coefficients of attachment (detachment) of electrons on the temperature of electrons during heating of the ionosphere [9].

Figure $8 \mathrm{~b}$ shows the values of the vertical velocity averaged over a time interval of $5 \mathrm{~min}$ with a range of -3 to $+5 \mathrm{~m} / \mathrm{s}$. You can see an irregular change in direction of speed with fluctuations around zero. In the time interval 13:00-13:30 LT, mainly downward movements with a velocity of up to $0.5-5.2 \mathrm{~m} / \mathrm{s}$ were observed.

The relaxation times were $0.6 \mathrm{~s}$ at $65.8 \mathrm{~km}$ and $1.35 \mathrm{~s}$ at $75.6 \mathrm{~km}$. Note that after $15 \mathrm{~h}$, the $30-\mathrm{min}$ heating was stopped and only the lower ionosphere was diagnosed by the API technique. When $\tau$ averaging, we did not take into account the time interval after $15 \mathrm{~h}$. Vertical movements occurred with a change in the direction of the velocity, similar to the September 11 observations.

Thus, the statement that the lower ionosphere at mesospheric heights is distinguished by highly developed dynamics has once again received experimental confirmation. As our previous researches, the results obtained on 11 and 12 September 2019 showed that at altitudes of 60-90 km vertical movements occur with an irregular change in the direction of the vertical velocity. If the limits of changes in the "instantaneous" velocity values (once every $15 \mathrm{~s}$ ) were from $-10 \mathrm{~m} / \mathrm{s}$ to $+10 \mathrm{~m} / \mathrm{s}$, then velocity values averaged over $5 \mathrm{~min}$ varied from -5 to $+5 \mathrm{~m} / \mathrm{s}$. There is still little information about vertical motions in the lower ionosphere in scientific publications. The method based on measuring the phase of the signal scattered by irregularities allows it to be determined with high accuracy. The error of a single measurement of speed does not exceed $0.08 \mathrm{~m} / \mathrm{s}$ [9]. 


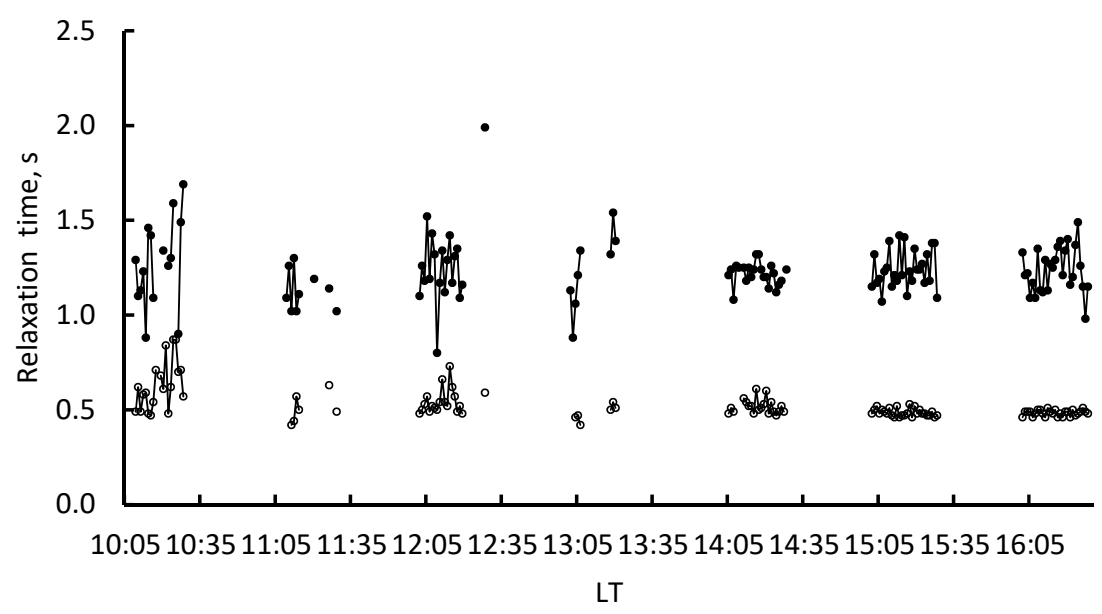

(a)

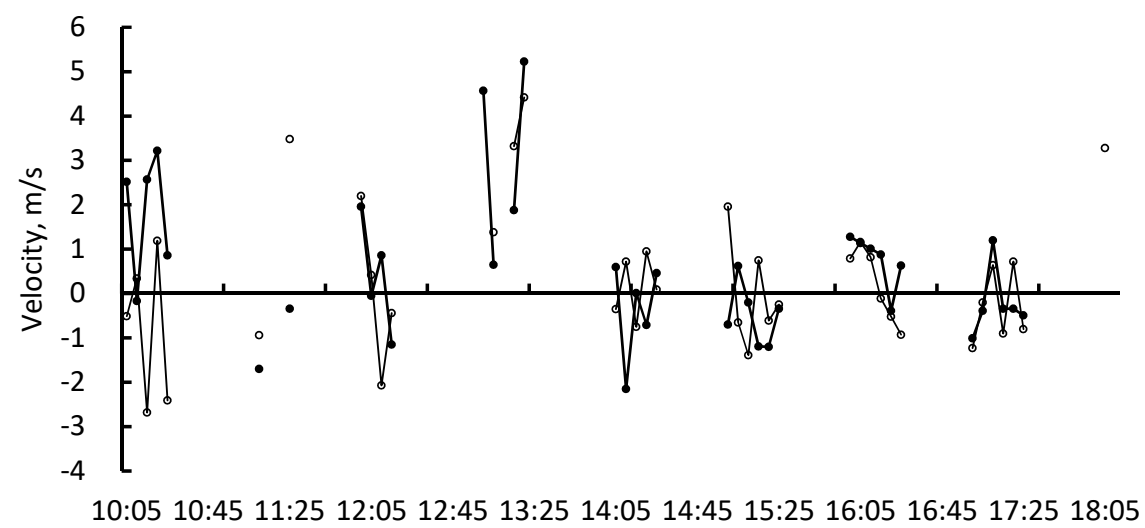

LT

(b)

Figure 8. The time dependence of the relaxation time averaged over $1 \mathrm{~min}(\mathbf{a})$ and the time dependence of the vertical velocity averaged over $5 \mathrm{~min}$ (b) on heights of $65.8 \mathrm{~km}$ (circles) and $75.6 \mathrm{~km}$ (points) for 11 September 2019.

The comparison of the scattered-signal characteristics, which were obtained in [36] on ozone-measurement days during long-term ionospheric heating and on the reference days without it, was indicative of the perturbation of the lower ionosphere during $30 \mathrm{~min}$ heating. This means that the plasma parameters of the lower ionosphere the mesospheric altitudes varied due to heating. This variation resulted in an increase in the variations of the amplitude and relaxation time of the scattered signal, as well as the vertical velocity of the medium in the $\mathrm{D}$ and $\mathrm{E}$ regions under the influence of the artificial turbulization of the medium. Unfortunately, in the experiment the results of which are given above, the control day could not be organized; therefore, we did not make such a comparison. 


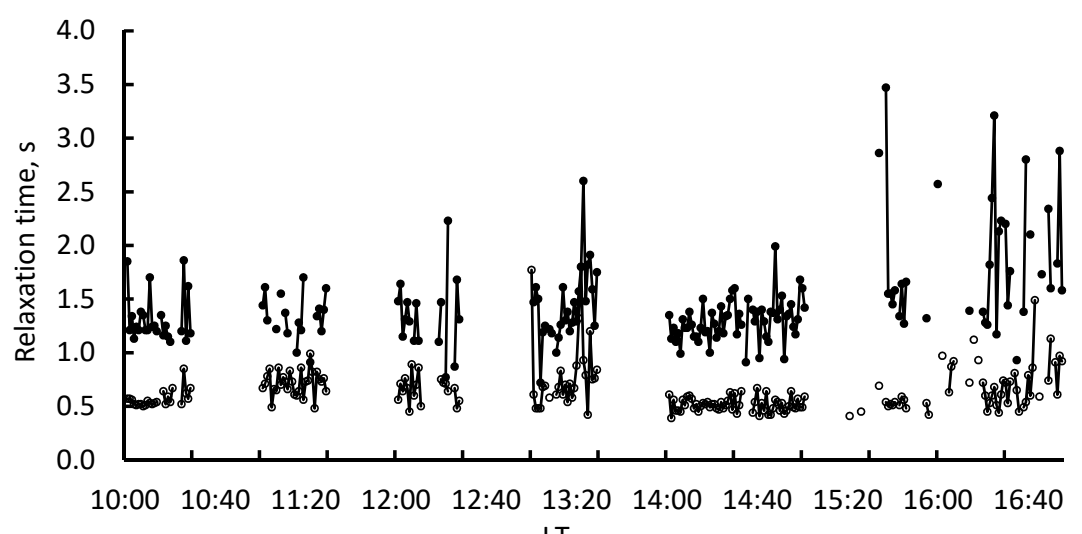

LT

(a)

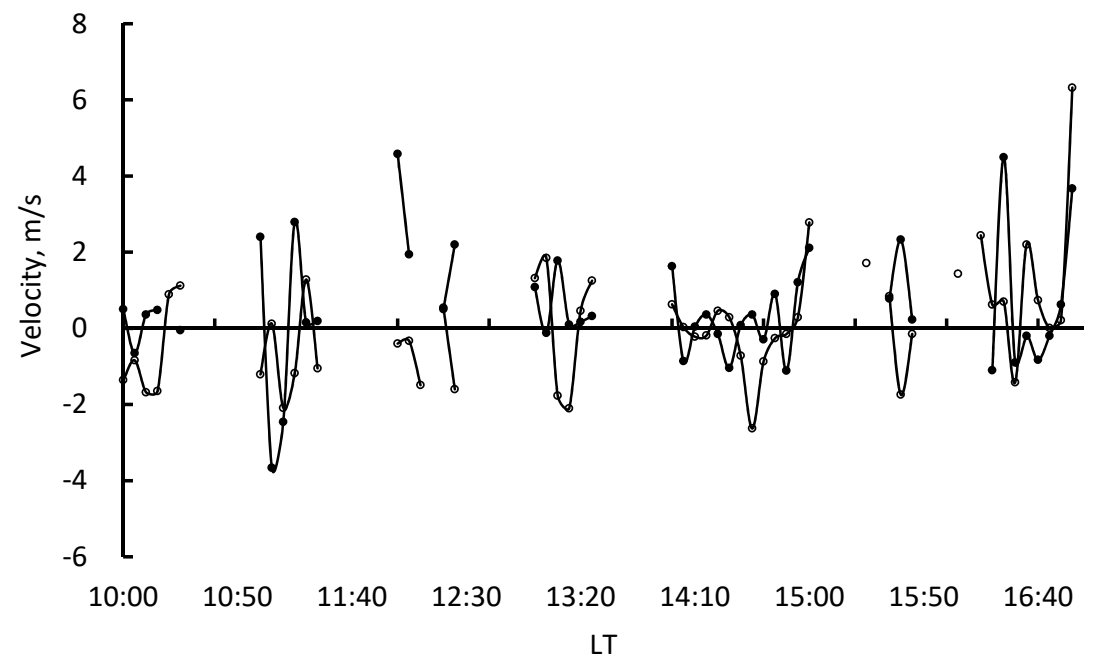

(b)

Figure 9. The time dependence of the relaxation time averaged over $1 \mathrm{~min}(\mathbf{a})$ and the time dependence of the vertical velocity averaged over $5 \mathrm{~min}$ (b) on heights of $65.8 \mathrm{~km}$ (circles) and $75.6 \mathrm{~km}$ (points) for 12 September 2019.

The method for studying the ionosphere and the neutral atmosphere, based on the creation and detection of artificial periodic irregularities, makes it possible to determine the temperature of the neutral component at an altitude above, as a rule, $90 \mathrm{~km}$, where the irregularities relax under the influence of ambipolar diffusion. The method for determining the temperature is described in detail in $[59,62]$. Although these heights already refer to the E-region or the lower thermosphere, and we are presenting variations of the parameters of the lower part of the D-region, we find it important to consider the temperature variations at these heights.

Figure 10 shows the time dependence of the neutral component temperature for 11 September 2019. Each dot on the graph is obtained by averaging data over $1 \mathrm{~min}$. Temperature determination error does not exceed $10 \%$. 


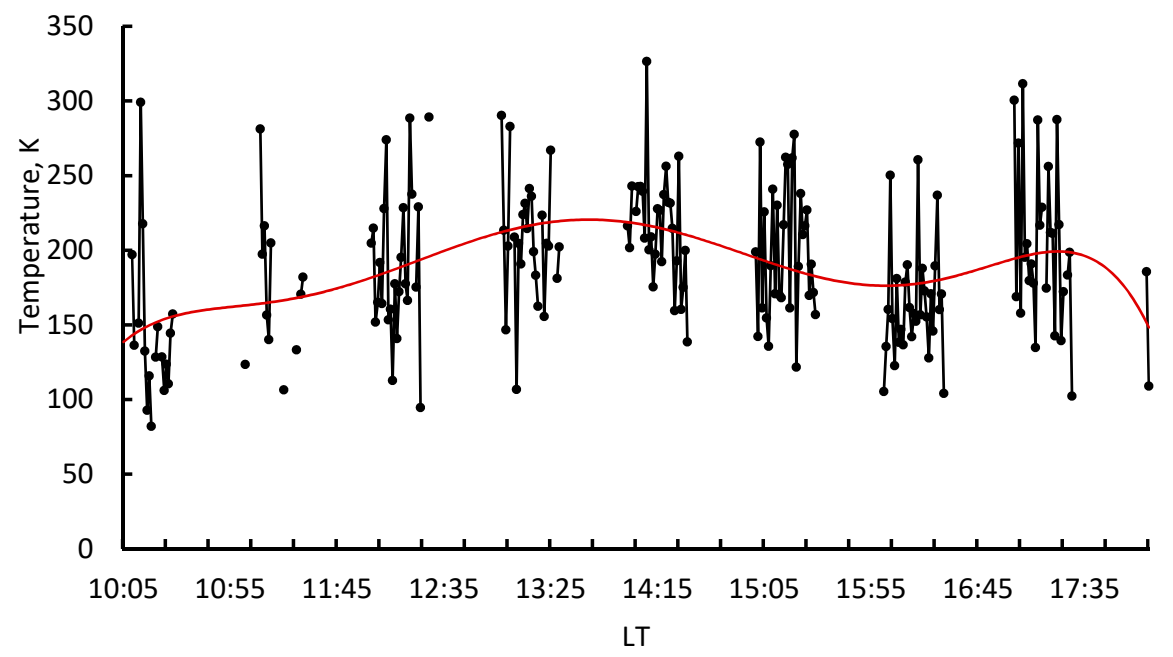

Figure 10. Time dependence of the neutral component temperature for 11 September 2019. Each dot on the graph is obtained by averaging data over $1 \mathrm{~min}$.

We found that the temperature of the neutral component at an altitude of $100 \mathrm{~km}$ varied within 100-300 km. Significant rapid temperature variations were observed with an average value of 190-200 $\mathrm{K}$. The sixth order polynomial trend line is marked in red. It shows approximately the tendency of change in the temperature of the neutral atmosphere on the day of spectral measurements in the time intervals between the sessions of heating the ionosphere. It can be roughly assumed that temperature variations have a wavy appearance with a quasi-period of 3.5-4 $\mathrm{h}$.

\section{Discussion}

\subsection{Internal Gravity Waves}

Some reasons for changes in the ozone spectrum can be considered. In [29,30], to explain the decrease in the atmospheric emission spectrum in the ozone line, which correlates with the periods of switching on the powerful emission of the SURA facility, a hypothesis was proposed about the influence of internal gravitational waves (IGW). Generation of IGW during periodic heating of E-region of the ionosphere (dynamo region) was considered. In [66,67], it is reported that IGW were excited when the SURA facility emitted powerful radio waves on long cycles. The IGW propagation down to the heights of the mesosphere should have caused a change in the temperature and pressure of the neutral atmosphere. In turn, this should affect the ozone content and the associated microwave spectrum. The IGW influence on the change in the emission spectrum of the atmosphere in the ozone line, regardless of the method of wave excitation are considered in [29,30]. For this, on the basis of the polarization relations for IGW, a relationship is obtained between the change in the spectrum intensity and the concentration of particles, provided that the change in the temperature of the neutral component is proportional to the change in the concentration of molecules. Thus, IGW generated by a source of powerful radio emission, including in the upper atmosphere, propagating down to mesospheric heights, change the temperature of the mesosphere. Changes in ambient temperature, in turn, affect changes in ozone concentration.

The hypothesis about the influence of IGW on ozone variations during heating, which was proposed in $[29,30]$ is critically discussed in [68] based on consideration of the features of ozone photochemistry in the stratosphere-mesosphere region. In it, the authors indicate that the values of the decrease in ozone concentration given in [29-31] are at the level of natural fluctuations. In addition, they indicate that when the ionosphere is heated, the small neutral components do not change. We present the results of experiments in which the changes in the spectrum intensity are small. However, observations [29-31,36] convincingly confirm a decrease in the measured emission spectrum of the atmosphere in the ozone line and, accordingly, in the concentration of mesospheric ozone at an altitude 
of $60 \mathrm{~km}$, which correlates with the effect of powerful radio emission from the facility on the ionospheric plasma. The influence of naturally occurring IGW on ozone in the stratosphere and mesosphere was considered in $[3,12,69,70]$. A review of the influence of IGW on the middle atmosphere is given in [70].

The authors [68] note the difficulty of explaining the obtained effects and the need to measure several characteristics of the ionosphere and neutral atmosphere when heating ozone experiments are carry out. We have taken into account this wish by applying additional diagnostics of the ionosphere by the method of the API creation when measuring the ozone emission spectrum.

\subsection{Modification of the D-Region Parameters under Artificial Disturbance of the Ionosphere}

Under the influence of powerful radio emission on the ionosphere, the temperature of electrons increases and their concentration changes [26,27,71-74]. In the D-region (60-90 km), the temperature dependence of the electron recombination coefficient $\alpha_{\mathrm{e}}$ with positive ions is expressed by the formula $\alpha_{e}\left(T_{e}\right)=\alpha_{e 0}\left(T_{e} / T_{e 0}\right)^{-b}$ where $\mathrm{b}=0.5-1.5$ and $\alpha_{\mathrm{e} 0}$ is undisturbed value of the recombination rate. In the D-region $T_{e 0}=T_{n}$, where $T_{n}$ is ambient neutral temperature $[55,57,72,75]$. With an increase in the electron temperature, the coefficient of dissociative recombination decreases. This process causes an increase in the electron concentration with a characteristic time $t=1 / \alpha_{e} \cdot N_{e}$, which at the heights of the D-region ranges from 10 to $60 \mathrm{~min}$. Note that the effect of recombination processes during heating predominates in the upper part of the D-region at heights above $70 \mathrm{~km}$. In its lower part, the main role during heating is played by the temperature dependences of the electron attachment and detachment coefficients.

The influence of heating the D-region on the modification in the attachment and detachment coefficients of electrons, the coefficient of ion-electron recombination are discussed in detail in $[4,57,75]$ and the dependences of these coefficients on the electron temperature are given. In [75], on the basis of the ionization balance equations and the altitude distribution of the heating wave power, the results of calculations of changes in the electron density with height in the region D are given taking into account the processes of electron attachment, detachment and dissociative recombination. It is shown that at an altitude of 60 and below, variations in the electron density are controlled by the electron attachment process, and above, recombination processes begin to influence. These two effects compete to determine the electron density distribution in the D-region during the ionosphere heating by powerful radio waves.

In [9], the process of API formation in the D-region is considered in detail. In [9,54-57], the modeling of the altitude dependence of the relaxation time of the scattered signal was carried out. It was shown that up to an altitude of $75-77 \mathrm{~km}$ this dependence is explained well on the basis of aeronomic processes with one negative oxygen ion. Above, it is necessary to take into account the reactions of negative oxygen ions with atomic oxygen. Experiments on studying the D- region by the API technique showed that the relaxation time of the signal scattered by irregularities in the lower part of the D-region is affected by the process of detachment of electrons from negative ions. In [54-57], the estimates of the attachment and detachment coefficients are made on the basis of measurements of the relaxation time of the scattered signal.

The results of measuring of the electron temperature, the concentration of negative ions and electrons in the heated the D-region in an experiment in the daytime in November 2006 at the EISCAT heater and their simulating using SIC model present in $[76,77]$. The results of measuring the concentration of negative ions are presented. It rises rapidly with increasing electron temperature.

Experiments on the heating of the D-region with the measurement of the electron concentration by the method of partial reflection technique have shown [78] that with an effective heating power of 80-100 MW, the electron temperature $\mathrm{T}_{\mathrm{e}}$ increased by no more than $40 \%$ at an altitude of $70 \mathrm{~km}$, while the electron concentration decreased by $5-7 \%$. In this regard, it is difficult to expect pronounced heating effects with a small effective heating power.

Taking into account the temperature dependences of the attachment and recombination coefficients on the electron temperature, which increases when the ionosphere is exposed to powerful radio 
emission $\beta\left(\mathrm{T}_{\mathrm{e}}\right)$ and $\alpha\left(\mathrm{T}_{\mathrm{e}}\right)$, in our opinion, allows us to qualitatively explain the decrease in the content of mesospheric ozone at an altitude of $60 \mathrm{~km}$.

In the lower part of the D-region of the ionosphere (below $70 \mathrm{~km}$ ), negative ions play a significant role in chemical reactions, where they are abundant. It is known $[2,5,79,80]$ that at the altitude of $50-60 \mathrm{~km}$ negative ions dominate over electrons $(\lambda \gg 1)$, where $\lambda$ is the ratio of the concentration of negative ions to the of electrons concentration $\mathrm{N}_{\mathrm{e}}$. The main source of negative ions is the attachment of electrons to oxygen molecules in triple collisions.

Primary $\mathrm{O}_{2}^{-}$ions are formed due to the adhesion of electrons to oxygen molecules in the process of triple collisions of an electron with molecules, for example $\mathrm{O}_{2}+e+\mathrm{O}_{2} \rightarrow \mathrm{O}_{2}^{-}+\mathrm{O}_{2}$. The process of formation of primary ions $\mathrm{O}_{2}^{-}$is well known. The coefficient of electron attachment to oxygen molecules $\beta$ depends on the electron [74] and depends on temperature and density of the atmosphere, varying in a wide range of values. The appearance of $\mathrm{O}_{2}^{-}$ions is the beginning of a long chain of ion-atomic reactions with the formation of new ions.

At an altitude at which the atmospheric temperature is $\mathrm{T}=230-250 \mathrm{~K}(\mathrm{~h}=60-65 \mathrm{~km})$, the a variation of the attachment rate coefficient $\beta$ depending on the variation in the electron temperature can be approximately written as $\Delta \beta / \beta \approx a \cdot \Delta T_{e} / T_{e o}$, where $\mathrm{a}=2$ and $\mathrm{T}_{\mathrm{e} 0}=\mathrm{T}_{\mathrm{n}}$ [56]. That is, with an increase in the temperature of electrons, including that occurring during heating (disturbance) of the ionosphere by powerful radio waves, the attachment rate coefficient of electrons to oxygen molecules increases. As a result, the electron concentration decreases, but the concentration of negative oxygen ions increases and, accordingly, the value of the relative concentration of negative ions increases too. That is, when the region $\mathrm{D}$ is heated, a redistribution of negative particles occurs. The growth process of the attachment coefficient $\beta$ is fast with a characteristic time of 0.1-1.0 s [75]. The rate of detachment of electrons $\gamma$ from negative ions $\mathrm{O}_{2}^{-}$is determined by the concentrations of atomic $\mathrm{O}$ and excited oxygen $O^{2}\left({ }^{1} \Delta_{g}\right)$ and the rate of photo detachment $[55,57]$.

The reactions of ozone with negative ions, as a result of which the ozone concentration decreases are well known $[1,2,79,81,82]$. One of them is the reaction with the negative ion of molecular oxygen $\mathrm{O}_{2}^{-}+\mathrm{O}_{3} \rightarrow \mathrm{O}_{3}^{-}+\mathrm{O}_{2}$ with the reaction constant $k=3.5 \cdot 10^{-10} \mathrm{~cm}^{3} \mathrm{~s}^{-1}$. The oxygen molecule then attaches an electron to form a negative oxygen ion, which reacts with ozone, decreasing its concentration.

Let us qualitatively consider the reaction of ozone with $\mathrm{O}_{2}^{-}$when the ionosphere is impacted to powerful radio emission. When the ionosphere is heated, a redistribution of negative particles occurs in 0.1-1.0 s and the concentration of negative ions increases, the concentration of electrons decreases. The number of interactions (reactions) of a negative oxygen ion with ozone) increases, as a result of which the concentration of ozone decreases. In this case, the concentration of the ozone ion increases. Estimations made on the base theory [72] and in accordance with the conditions of our experiment, at an altitude of $60 \mathrm{~km}$ with the ratio of the electric field to the plasma field about 1.2, the electron temperature, depending on the D-region condition can increase up to (20-40)\% relative to its unperturbed value $250 \mathrm{~K}$. This, according to [82], should lead to an increase in the concentration of negative ions of the oxygen molecule by (15-20)\% and, probably, to approximately the same increase in the concentration of ozone ions. The latter will cause a decrease in the concentration of molecular ozone, which, in turn, will lead to a decrease in the intensity of the recorded microwave radiation. This estimate of the decrease in the radiation intensity generally corresponds to the results of measurements of the intensity of the atmospheric radiation spectrum in the ozone line.

It was noted above that the influence of recombination processes upon heating predominates in the upper part of the D-region at heights above $70 \mathrm{~km}$. In its lower part, the main role during heating is played by the temperature dependences of the adhesion and detachment coefficients of electrons [54,75]. Disturbance of the ionosphere and heating of the electronic component with the measurement of the emission spectrum of the atmosphere in the ozone line by microwave radiometry were carried out for $30 \mathrm{~min}$. During this time, the variations in the electron concentration begin to be influenced by recombination processes. In this case, the electron concentration increases, and the concentration of negative ions oxygen decreases. However, recombination processes affect the 
plasma redistribution at heights of the upper part of the D-region above $80 \mathrm{~km}$. Measurements of the mesospheric ozone spectrum are given for an altitude of $60 \mathrm{~km}$.

We consider more important changes in the mesosphere due to horizontal and vertical motions, which can affect the transfer of the neutral component during the measurement of each ozone spectrum. The movements also affect the conditions of API formation, the characteristics of scattered signals and the temperature of the neutral component and the speed of vertical movement determined from them. Rapid variations of these parameters from session to session are shown in Figures 8-10.

We have presented some arguments that allow, in our opinion, to qualitatively explain the possibility of a decrease in the ozone concentration and spectrum under the action of powerful high-frequency radio emission, which causes the electrons to be heated. Quantitative calculations require detailed consideration of ionic chemistry at mesospheric altitudes under artificial disturbance of the ionosphere.

Unfortunately, in contrast to the experiments in September 2016, it was not possible to carry out control measurements on a day free from continuous high-frequency heating of the ionosphere. Observations on 12 September 2019 from 14:00 to 17:00 were carried out without heating; however, a significant change in the state of the lower ionosphere with the appearance of an intense sporadic E layer does not allow us to consider this period of time as a control time. Comparison of the characteristics of the scattered signal obtained on the days of ozone spectrum measurements during continuous heating of the ionosphere, and on control days according to the results of the experiment in September 2016, indicated a strong disturbance of the lower ionosphere during a long 30-min heating [36]. This means that the plasma of the lower ionosphere, including at mesospheric altitudes, where the effect of heating on the emission spectrum of the atmosphere in the ozone line was studied, reacted to heating by changing its parameters. This effect was expressed in an increase in variations in the amplitude and relaxation time of the scattered signal, as well as in the vertical plasma velocity in D- and E-regions under the influence of artificial turbulization of the environment.

\section{Conclusions}

The paper presents and discusses the results of comprehensive studies of the Earth's lower ionosphere at mesospheric heights by creating artificial periodic irregularities of the ionospheric plasma with simultaneous measurement of the atmospheric emission spectrum in the ozone line by ground-based microwave radiometry. The purpose of the experiments was to study the possible effect of artificial influence on the ionosphere by powerful high-frequency radio emission from the SURA facility on the concentration of mesospheric ozone at an altitude of $60 \mathrm{~km}$ The correlation between the decrease in the intensity of the emission spectrum of the atmosphere in the ozone line and the period of switching on the powerful heating facility, found in other observations, was confirmed [29-31,36]. Diagnostics of the lower ionosphere, carried out by the method of resonant scattering of radio waves on the periodic irregularities, showed that during the heating on period strong disturbances in the D-region were observed.

In September 2016, these disturbances manifested themselves in the dynamic rearrangement of the lower part of the D-region, which led to degradation in the conditions for the API formation and to disturbance of the electron density in the D-region. Wave-like variations in the velocity of vertical motion in D- and E-regions and in the temperature of the neutral component at altitudes were also observed [36]. In September 2019, the decrease in the intensity of the ozone emission spectrum during the heating of the ionosphere was on average from $7 \%$ to $12 \%$, in some sessions up to $20 \%$. The measurement results strongly depended on the condition of the lower ionosphere. From the altitude profiles of the relaxation time of the scattered signal, the lower boundary of the altitude region enriched in atomic oxygen was determined. It was at the altitude of $74-77 \mathrm{~km}$. The velocity of vertical plasma movement, determined from measurements of the phase of the scattered signal, changed direction from session to session in the D-region. We assumed that a possible reason for the 
effect of heating on mesospheric ozone is the redistribution of electrons and negative ions due to the temperature dependence of the electron attachment coefficient to oxygen molecules.

To substantiate the conclusion about the effect of ionospheric heating on mesospheric ozone, the content of which is significantly lower than in the stratosphere, a detailed analysis of ionic chemistry in the D-region and the calculation of perturbations taking into account photochemistry and ion-recombination processes are required. It is necessary to simultaneously measure the ozone emission spectrum, the electron density in the D-region, and parameters of the neutral component. So far, no such observations have been made.

Author Contributions: Conceptualization, N.V.B. and Y.Y.K.; methodology, N.V.B. and Y.Y.K.; software, I.N.Z.; validation, N.V.B., Y.Y.K. and I.N.Z.; investigation, N.V.B., Y.Y.K. and I.N.Z.; writing-original draft preparation, N.V.B. and Y.Y.K.; writing-review and editing, N.V.B.; visualization, I.N.Z.; supervision, N.V.B.; project administration, N.V.B. All authors have read and agreed to the published version of the manuscript.

Funding: This research was funded by Russian Science Foundation, grant number 20-17-00050 (N.V.B. and I.N.Z.) and Russian Foundation for Basic Research, grant number 18-45-520009 (Y.Y.K.).

Acknowledgments: The authors are grateful to G.I. Grigoriev for helpful discussions of the experimental results. In 2020, the modernization of the SURA facility was supported by the Ministry of Science and Higher Education, Russian Federation. Grant received within the framework of the federal purposeful program "Research and Development in Priority Areas for the Development of the Russian Science and Technology Complex for 2014-2020". The unique identifier for the project is FMEFI62020X0003. Contract N 075-15-2020-529.

Conflicts of Interest: The authors declare no conflict of interest.

\section{References}

1. Reid, I.M. MF and HF radar techniques for investigating the dynamics and structure of the 50 to $110 \mathrm{~km}$ height region: A review. Prog. Earth Planet. Sci. 2015, 2, 33. [CrossRef]

2. Brasseur, G.P.; Solomon, S. Aeronomy of the Middle Atmosphere, 3rd ed.; Springer: Dordrecht, The Netherlands, 2005; p. 651.

3. Garcia, R.R.; Solomon, S. The effect of breaking gravity waves on the dynamics and chemical composition of the mesosphere and lower thermosphere. J. Geophys. Res. Atmos. 1985, 90, 3850-3868. [CrossRef]

4. Morozova, A.L.; Ribeiro, P.; Blanco, J.J.; Barlyaeva, T.V. Temperature and pressure variability in mid-latitude low atmosphere and stratosphere-ionosphere coupling. Adv. Space Res. 2020, 65, 2184-2202. [CrossRef]

5. Nicolet, M.; Aikin, A.C. The formation of the D region of the ionosphere. J. Geophys. Res. 1960, 65, 1469-1483. [CrossRef]

6. Reid, G.C. Ion chemistry in the D-region. Adv. At. Mol. Phys. 1976, 12, 375-412. [CrossRef]

7. Pavlov, A.V. Photochemistry of Ions at D-region Altitudes of the Ionosphere: A Review. Surv. Geophys. 2014, 35, 259-334. [CrossRef]

8. Bryunelli, B.E.; Namgaladze, A.A. Physics of the Ionosphere [in Russian]; Nauka: Moscow, Russia, $1988 ;$ p. 527.

9. Belikovich, V.V.; Benediktov, E.A.; Tolmacheva, A.V.; Bakhmet'eva, N.V. Ionospheric Research by Means of Artificial Periodic Irregularities; Copernicus GmbH: Katlenburg-Lindau, Germany, 2002; p. 160.

10. Sugita, T.; Nakajima, H.; Yokota, T.; Kanzawa, H.; Gernandt, H.; Herber, A.; Von Der Gathen, P.; König-Langlo, G.; Sato, K.; Dorokhov, V.; et al. Ozone profiles in the high-latitude stratosphere and lower mesosphere measured by the Improved Limb Atmospheric Spectrometer (ILAS)-II: Comparison with other satellite sensors and ozonesondes. J. Geophys. Res. 2006, 111, D11S02. [CrossRef]

11. Smith, A.K.; Harvey, V.L.; Mlynczak, M.G.; Funke, B.; García-Comas, M.; Hervig, M.; Kaufmann, M.; Kyrölä, E.; López-Puertas, M.; McDade, I.; et al. Satellite observations of ozone in the upper mesosphere. Geophys. Res. Atmos. 2013, 118, 5803-5821. [CrossRef]

12. Marsh, D.R.; Skinner, W.R.; Marshall, A.R.; Hays, P.B.; Ortland, D.A.; Yee, J.-H. High Resolution Doppler Imager observations of ozone in the mesosphere and lower thermosphere. J. Geophys. Res. Atmos. 2002, 107, 4390. [CrossRef]

13. Schneider, N.; Selsis, F.; Urban, J.; Lezeaux, O.; Noë, J.D.L.; Ricaud, P. Seasonal and Diurnal Ozone Variations: Observations and Modeling. J. Atmos. Chem. 2005, 50, 25-47. [CrossRef] 
14. Hocke, K.; Lainer, M.L.M.; Bernet, L.A.L.; Kämpfer, N. Mesospheric Inversion Layers at Mid-Latitudes and Coincident Changes of Ozone, Water Vapour and Horizontal Wind in the Middle Atmosphere. Atmosphere 2018, 9, 171. [CrossRef]

15. Kutiev, I.; Tsagouri, I.; Perrone, L.; Pancheva, D.; Mukhtarov, P.; Mikhailov, A.; Lastovicka, J.; Jakowski, N.; Buresova, D.; Blanch, E.; et al. Solar activity impact on the Earth's upper atmosphere. J. Space Weather Space Clim. 2013, 3, A06. [CrossRef]

16. Lean, J.L. Observation of the diurnal variation of atmospheric ozone. J. Geophys. Res. Oceans. 1982, 87, 4973-4980. [CrossRef]

17. Degenstein, D.A.; Gattinger, R.L.; Lloyd, N.D.; Bourassa, A.E.; Wiensz, J.T.; Llewellyn, E.J. Observations of an Extended Mesospheric Tertiary Ozone Peak. J. Atmos. Sol. Terr. Phys. 2005, 67, 1395-1402. [CrossRef]

18. McInerney, J.M.; Marsh, D.R.; Liu, H.-L.; Solomon, S.C.; Conley, A.J.; Drob, D.P. Simulation of the 21 August 2017 solar eclipse using the Whole Atmosphere Community Climate Model-eXtended. Geophys. Res. Lett. 2018, 45, 3793-3800. [CrossRef]

19. Kulikov, Y.Y.; Krasil'nikov, A.A.; Demkin, V.M.; Ryskin, V.G. Variations in the concentration of mesospheric ozone during the total solar eclipse of March 29, 2006, from microwave radiometric data. Izv. Atmos. Ocean. Phys. 2008, 44, 486-490. [CrossRef]

20. Yasyukevich, A.S.; Ratovsky, K.G.; Kulikov, Y.Y.; Klimenko, M.V.; Klimenko, V.V.; Bessarab, F.S.; Korenkov, Y.N.; Marichev, V.N.; Kolesnik, S.A. Changes in the stratosphere and ionosphere parameters during the 2013 major stratospheric warming. In Proceedings of the 2018 2nd URSI Atlantic Radio Science Meeting (AT-RASC), Meloneras, Spain, 28 May-1 June 2018; Volume 2, p. 8471322. [CrossRef]

21. Bochkovsky, D.A.; Marichev, V.N.; Virolainen, Y.A.; Poberovsky, V.A.; Timofeyev, Y.M.; Kulikov, Y.Y.; Ryskin, V.G. Ground based microwave monitoring of middle atmosphere ozone above Peterhof and Tomsk during stratospheric warming in the winter of 2013-2014. Radiophys. Quantum Electron. 2016, 59, $270-277$. [CrossRef]

22. Chalapathi, G.V.; Eswaraiah, S.; Prasanth, P.V.; Lee, J.; Kumar, K.N.; Kim, Y.H. Unusual Changes in Stratospheric Ozone and Water Vapor Over Antarctica and its Relation to Mesosphere Dynamics during a Minor Sudden Stratosphere Warming. Int. J. Curr. Res. Rev. 2018, 10, 53. [CrossRef]

23. Muscari, G.; Pezzopane, M.; Romaniello, V.; De Safra, R.L.; Bianci, C.; Fiocco, G. On the potencial impact of large electron concentration on mesospheric ozone. Mem. Della Soc. Astron. Ital. 2005, 76, 1007-1010.

24. Pakhomov, S.V.; Knyazev, A.K. Ozone in the mesosphere and electron density in the midlatitude D-region. Geomagn. Aeron. 1988, 28, 976-979.

25. Langematz, U. Stratospheric ozone: Down and up through the Anthropocene. ChemTexts 2019, 5. [CrossRef]

26. Gurevich, A.V. Nonlinear Phenomena in the Ionosphere. Physics and Chemistry in Space; Springer: New York, NY, USA, 1978; p. 372. [CrossRef]

27. Gurevich, A.V. Nonlinear effects in the ionosphere. Phys. Uspekhi. 2007, 50, 1091-1121. [CrossRef]

28. Frolov, V.L.; Bakhmet'eva, N.V.; Belikovich, V.V.; Vertogradov, G.G.; Vertogradov, V.G.; Komrakov, G.P.; Kotik, D.S.; Mityakov, N.A.; Polyakov, S.V.; Rapoport, V.O.; et al. Modification of the Earth's ionosphere by high-power high-frequency radio waves. Phys. Uspekhi. 2007, 50, 315-324. [CrossRef]

29. Kulikov, Y.Y.; Frolov, V.L.; Grigor'ev, G.I.; Demkin, V.M.; Komrakov, G.P.; Krasilnokov, A.A.; Ryskin, V.G. Response of mesospheric ozone to the heating of the lower ionosphere by high-power HF radio emission. Geomagn. Aeron. (Engl. Transl.) 2013, 53, 96-103. [CrossRef]

30. Kulikov, Y.Y.; Krasilnikov, A.A.; Grigoriev, G.I.; Frolov, V.L. Variations in the microwave radiation of the mesosphere during heating of the ionosphere with high-power radio waves. Radiophys. Quantum Electron. 2012, 55, 51-58. [CrossRef]

31. Kulikov, Y.Y.; Frolov, V.L. Influence of the artificially disturbed ionosphere on the mesospheric ozone. Russ. J. Phys. Chem. B 2013, 7, 692-695. [CrossRef]

32. Kulikov, Y.Y.; Krasilnikov, A.A.; Shchitov, A.M. New Mobile Ground-Based Microwave Instrument to Research of Stratospheric Ozone (Some Results of Observations). In Proceedings of the 2007 International Kharkov Symposium Physics and Engineering of Microwaves, Millimeter, and Submillimeter Waves (MSMW), Kharkov, Ukraine, 25-30 June 2007; pp. 62-66. [CrossRef]

33. Keating, G.M.; Pitts, M.C.; Young, D.F. Ozone reference models for the middle atmosphere. Adv. Space Res. 1990, 10, 317-355. [CrossRef] 
34. Barnett, J.J.; Corney, M. A middle atmosphere temperature reference model from satellite measurements. Adv. Space Res. 1985, 5, 125-134. [CrossRef]

35. Krasil'nikov, A.A.; Kulikov, Y.Y.; Mazur, A.B.; Ryskin, V.G.; Serov, N.V.; Fedoseev, L.I.; Shvetsov, A.A. Detection of "ozone" clouds in the upper stratosphere of the Earth by means of microwave radiometry technique. Geomag. Aeron. (Engl. Transl.) 1997, 37, 385-391.

36. Andrianov, A.F.; Bakhmet'eva, N.V.; Vyakhirev, V.D.; Kalinina, E.E.; Krasilnikov, A.A.; Kulikov, Y.Y. A Study of the Density Variations of Mesospheric Ozone in the Case of Ionospheric Perturbation by the "Sura" Facility Radiation with Simultaneous Diagnostics of Ionospheric Plasma. Radiophys. Quantum Electron. 2019, 62, 326-341. [CrossRef]

37. Available online: http://forecast.izmiran.ru/indexb.php (accessed on 12 September 2019).

38. Connor, B.J.; Siskind, D.E.; Tsou, J.J.; Parrish, A.; Remsberg, E.E. Ground-based microwave observations of ozone in the upper stratosphere and mesosphere. J. Geophys. Res. 1994, 99, 16757-16770. [CrossRef]

39. De la Noe, J.; Baudry, A.; Perault, M.; Dierich, P.; Monnanteuil, N.; Colmont, J.M. Measurements of the vertical distribution of ozone by ground-based microwave techniques at the Bordeaux Observatory during the June 1981 intercomparison campaign. Planet. Space Sci. 1983, 31, 737-741. [CrossRef]

40. De la Noe, J.; Turati, C.; Baudry, A.; Monnanteuil, N.; Colmont, J.M.; Dierich, P. Ground-Based Microwave Observations of Mesospheric Ozone at the Bordeaux Observatory. Atmospheric Ozone. In Atmospheric Ozone: Proceedings of the Quadrennial Ozone Symposium Held in Halkidiki, Greece, 3-7 September 1984; Zerefos, C.S., Ghazi, A., Eds.; Springer: Dordrecht, The Netherlands, 1985; pp. 417-422.

41. Dumitru, M.C.; Hocke, K.; Kämpfer, N.; Calisesi, Y. Comparison and validation studies related to ground-based microwave observations of ozone in the stratosphere and mesosphere. J. Atmos. Sol. Terr. Phys. 2005, 68, 745-756. [CrossRef]

42. Ryskin, V.G.; Kulikov, Y.Y.; Krasilnikov, A.A.; Kukin, L.M.; Savchenko, V.R. Microwave diagnostics of chemical ozone destruction in the arctic stratosphere. Radiophys. Quantum Elelectron. 2007, 50, 870-876. [CrossRef]

43. Kulikov, Y.Y.; Poberovskii, A.V.; Ryskin, V.G.; Yushkov, V.A. Detection of Large Fluctuations in Ozone Content in the Middle Atmosphere during Sudden Stratospheric Warmings and Subpolar Latitudes of the Arctic. Geomagn. Aeron. 2020, 60, 254-262. [CrossRef]

44. Rozanov, S.B.; Zavgorodniy, A.S.; Ignatyev, A.N. Microwave measurements of variations in night mesospheric ozone over Moscow. In Proceedings Volume 11152, Remote Sensing of Clouds and the Atmosphere XXIV, SPIE Remote Sensing, Strasbourg, France, 9-12 September 2019; SPIE: Bellingham, WA, USA, 2019; Volume 11152. [CrossRef]

45. Belikovich, V.V.; Benediktov, E.A.; Getmantsev, G.G.; Ignat'ev, Y.A.; Komrakov, G.P. Scattering of radio waves from the artificial perturbed F region of the ionosphere (Engl. Translation). JETP Lett. 1975, 22, 243-244.

46. Fejer, I.A.; Djuth, F.T.; Gonzales, C.A. Bragg backscatter from plasma inhomogeneities due to a powerful ionospherically reflected radio waves. J. Geophys. Res. 1984, 89, 9145-9147. [CrossRef]

47. Djuth, F.T.; Groves, K.M.; Elder, J.H.; Shinn, E.R.; Quinn, J.M.; Villasenor, J.; Wong, A.Y. Measurements of artificial periodic inhomogeneities at HIPAS observatory. J. Geophys. Res. 1997, 102, 24023-24035. [CrossRef]

48. Rietveld, M.T.; Turunen, E.; Matveinen, H.; Goncharov, N.P.; Pollari, P. Artificial periodic irregularities in the auroral ionosphere. Ann. Geophys. 1996, 14, 1437-1453. [CrossRef]

49. Rietveld, M.T.; Goncharov, N.P. Artificial Periodic Irregularities from the Tromsø Heating facility. Adv. Space Res. 1998, 21, 693-696. [CrossRef]

50. Vierinen, J.; Kero, A.; Rietveld, M.T. High latitude artificial periodic irregularity observations with the upgraded EISCAT heating facility. J. Atmos. Sol. Terr. Phys. 2013, 105-106, 253-261. [CrossRef]

51. Hyssel, D.L.; McCarrick, M.J.; Fallen, C.T.; Vierinen, J. First artificial periodic inhomogeneity experiments at HAARP. GRL 2015, 42, 1033-1297. [CrossRef]

52. Bakhmetieva, N.V.; Grach, S.M.; Sergeev, E.N.; Shindin, A.V.; Milikh, G.M.; Siefring, C.L.; Bernhardt, P.A.; McCarrick, M. Artificial periodic irregularities in the high-latitude ionosphere excited by the HAARP facility. Radio Sci. 2016, 51, 999-1009. [CrossRef]

53. Bakhmetieva, N.V.; Grigor'ev, G.I.; Tolmacheva, A.V. Artificial periodic irregularities, hydrodynamic instabilities, and dynamic processes in the mesosphere-lower thermosphere. Radiophys. Quantum Electron. 2011, 53, 623-637. [CrossRef] 
54. Belikovich, V.V.; Benediktov, E.A.; Trunov, D.V. Height profiles of the amplitude and relaxation time of artificial periodic irregularities in the D-region. Geomagn. Aeron. 2000, 40, 733-738.

55. Belikovich, V.V.; Benediktov, E.A. Study of the Twilight D-Region of the Ionosphere using Artificial Periodic Inhomogeneities. Radiophys. Quantum Electron. 2002, 45, 458-464. [CrossRef]

56. Belikovich, V.V.; Razin, S.V. Formation of artificial periodic irregularities in the D region of the ionosphere, taking attachment and recombination processes into account. Radiofizika 1986, 29, 251-257. (In Russian)

57. Belikovich, V.V.; Benediktov, E.A. Investigation of the lower D-region of the ionosphere using artificial periodic irregularities. Radiofizika 1986, 29, 1283-1296. (In Russian)

58. Bakhmetieva, N.V.; Vyakhirev, V.D.; Kalinina, E.E.; Komrakov, G.P. Earth's lower ionosphere during partial solar eclipses according to observations near Nizhny Novgorod. Geomagn. Aeron. 2017, 57, 58-71. [CrossRef]

59. Bakhmetieva, N.V.; Belikovich, V.V. Results of studying the sporadic E layer by the method of resonant scattering of radio waves by artificial periodic inhomogeneities of the ionospheric plasma. Radiophys. Quantum Electron. 2008, 51, 862-873. [CrossRef]

60. Tolmacheva, A.V.; Belikovich, V.V.; Kalinina, E.E. Atmospheric parameters measured using artificial periodic irregularities with different spatial dimensions. Geomagn. Aeron. 2009, 49, 239-246. [CrossRef]

61. Bakhmet'eva, N.V.; Belikovich, V.V.; Egerev, M.N.; Tolmacheva, A.V. Artificial periodic irregularities, wave phenomena in the lower ionosphere and the sporadic E-layer. Radiophys. Quantum Electron. 2010, 53, 77-90. [CrossRef]

62. Tolmacheva, A.V.; Bakhmetieva, N.V.; Grigoriev, G.I.; Egerev, M.N. Turbopause range measured by the method of the artificial periodic irregularities. Adv. Space Res. 2019, 64, 1968-1974. [CrossRef]

63. Tolmacheva, A.V.; Belikovich, V.V. Measurements of the temperature and density of the upper atmosphere using artificial periodic irregularities during the summer seasons of 1999-2002. Int. J. Geomagn. Aeron. 2004, 5, 1-8, GI1008. [CrossRef]

64. Kagan, L.M.; Bakhmet'eva, N.V.; Belikovich, V.V.; Tolmacheva, A.V. Structure and dynamics of sporadic layers of ionization in the ionospheric E region. Radio Sci. 2002, 37, 1106-1123. [CrossRef]

65. Bakhmetieva, N.V.; Grigoriev, G.I.; Tolmacheva, A.V.; Zhemyakov, I.N. Investigations of Atmospheric Waves in the Earth Lower Ionosphere by Means of the Method of the Creation of the Artificial Periodic Irregularities of the Ionospheric Plasma. Atmosphere 2019, 10, 450. [CrossRef]

66. Chernogor, L.F.; Frolov, V.L. Traveling ionospheric disturbances generated due to periodic plasma heating by high-power high-frequency radiation. Radiophys. Quantum Electron. 2012, 55, 13-32. [CrossRef]

67. Chernogor, L.F.; Panasenko, S.V.; Frolov, V.L.; Domnin, I.F. Observations of the ionospheric wave disturbances using the Kharkov incoherent scatter radar upon RF heating of the near-earth plasma. Radiophys. Quantum Electron. 2015, 52, 79-91. [CrossRef]

68. Bekker, S.Z.; Kozlov, S.I.; Tasenko, S.V. Estimation of the ozone decrease possibility in the lower part of the D-region under the action of a powerful radiowave. Geomagn. Aeron. 2016, 56, 757-760. [CrossRef]

69. Hagen, J.; Hocke, K.; Stober, G.; Pfreundschuh, S.; Murk, A.; Kämpfer, N. First measurements of tides in the stratosphere and lower mesosphere by ground-based Doppler microwave wind radiometry. Atmos. Chem. Phys. 2020, 20, 2367-2386. [CrossRef]

70. Fritts, D.C.; Alexander, M.J. Gravity waves dynamics and effects in the middle atmosphere. Rev. Geophys. 2003, 41, 1003-1167. [CrossRef]

71. Ginzburg, V.L. The Propagation of Electromagnetic Waves in Plasmas, 2nd ed.; Pergamon Press: Oxford, UK, $1970 ;$ p. 615.

72. Gurevich, A.V.; Shvartsburg, A.B. Nelineinaya Teoriya Rasprostraneniya Radiovoln v Ionosfere; Nauka: Moscow, Russia, 1973; p. 272.

73. Holway, L.H.; Meltz, G. Heating of the Lower Ionosphere by Powerful Radio Waves. J. Geophys. Res. 1973, 78, 8402. [CrossRef]

74. Meltz, G.; Holway, L.H., Jr.; Tomljanovich, N.M. Ionospheric heating by powerful radio waves. Radio Sci. 1974, 9, 1049-1063. [CrossRef]

75. Tomko, A.A.; Ferraro, A.J.; Lee, H.S.; Mitra, A.P. A theoretical model of D-region ion chemistry modifications during high power radio wave heating. J. Atmos. Terr. Phys. 1980, 42, 275-285. [CrossRef]

76. Kero, A.; Vierinen, J.; Enell, C.-F.; Virtanen, I.; Turunen, E. New incoherent scatter diagnostic methods for the heated D-region ionosphere. Ann. Geophys. 2008, 26, 2273-2279. [CrossRef] 
77. Kovács, T.; Plane, J.M.C.; Feng, W.; Nagy, T.; Chipperfield, M.P.; Verronen, P.T.; Andersson, M.E.; Newnham, D.A.; Clilverd, M.A.; Marsh, D.R. D-region ion-neutral coupled chemistry (Sodankylä Ion Chemistry, SIC) within the Whole Atmosphere Community Climate Model (WACCM 4)-WACCM-SIC and WACCM-rSIC. Geosci. Model Dev. 2016, 9, 3123-3136. [CrossRef]

78. Bakhmetieva, N.V.; Vyakhirev, V.D.; Kalinina, E.E. (the article is being prepared for publication).

79. Mc Ewan, M.J.; Phillips, L.F.; Dalgarno, A. Chemistry of the Atmosphere. In Atmosphere and Oceanographic Sciences Library; Springer: Dordrecht, The Netherlands, 2005; Volume 32, p. 644.

80. Verronen, P.T.; Ulich, T.; Turunen, E.; Rodger, C.J. Sunset transition of negative charge in the D-region ionosphere during high-ionization conditions. Ann. Geophys. 2006, 24, 187-202. [CrossRef]

81. Enell, C.-F.; Kero, A.; Turunen, E.; Ulich, T.; Verronen, P.T.; Seppälä, A.; Marple, S.; Honary, F.; Senior, A. Effects of D-region RF heating studied with the Sodankylä Ion Chemistry mode. Ann. Geophys. 2005, 23, 1575-1583. [CrossRef]

82. Turunen, E.; Matveinen, H.; Tolvanen, J.; Ranta, H. D-region ion chemistry Model. In Handbook of Ionospheric Models; Schunk, R.W., Ed.; Utah State University: Logan, UT, USA, 1996; pp. 1-25.

Publisher's Note: MDPI stays neutral with regard to jurisdictional claims in published maps and institutional affiliations.

(C) 2020 by the authors. Licensee MDPI, Basel, Switzerland. This article is an open access article distributed under the terms and conditions of the Creative Commons Attribution (CC BY) license (http://creativecommons.org/licenses/by/4.0/). 